University of Nebraska - Lincoln

DigitalCommons@University of Nebraska - Lincoln

Agronomy \& Horticulture -- Faculty Publications

Agronomy and Horticulture Department

July 2004

\title{
Characterization of Humic Acid Fractions Improves Estimates of Nitrogen Mineralization Kinetics for Lowland Rice Soils
}

Nguyen Bao Ve

Can Tho Univ., CanTho, Vietnam

D. C. Olk

USDA-ARS

Kenneth G. Cassman

University of Nebraska-Lincoln, kcassman1@unl.edu

Follow this and additional works at: https://digitalcommons.unl.edu/agronomyfacpub

Part of the Plant Sciences Commons

Ve, Nguyen Bao; Olk, D. C.; and Cassman, Kenneth G., "Characterization of Humic Acid Fractions Improves Estimates of Nitrogen Mineralization Kinetics for Lowland Rice Soils" (2004). Agronomy \& Horticulture -Faculty Publications. 107.

https://digitalcommons.unl.edu/agronomyfacpub/107

This Article is brought to you for free and open access by the Agronomy and Horticulture Department at DigitalCommons@University of Nebraska - Lincoln. It has been accepted for inclusion in Agronomy \& Horticulture -Faculty Publications by an authorized administrator of DigitalCommons@University of Nebraska - Lincoln. 


\title{
Characterization of Humic Acid Fractions Improves Estimates of Nitrogen Mineralization Kinetics for Lowland Rice Soils
}

\author{
Nguyen Bao Ve, D. C. Olk,* and K. G. Cassman
}

\begin{abstract}
Nitrogen mineralization in irrigated lowland rice (Oryza sativa $\mathbf{L}$.) soils is poorly predicted by total soil $\mathrm{C}$ and $\mathrm{N}$. To improve its prediction, two humic acid fractions were extracted with $\mathrm{NaOH}$ from lowland rice soils of Vietnam and the Philippines to evaluate their influence on $\mathbf{N}$ mineralization kinetics during 84-d anaerobic incubations. Indicative of young organic matter, the mobile humic acid (MHA) fraction had a smaller $C / N$ ratio and optical density at $465 \mathrm{~nm}\left(E_{4}\right)$ than did the calcium humate (CaHA) fraction, which was extracted after removal of polyvalent cations from the soil. Nitrogen contents of both fractions combined represented 15 to $30 \%$ of total soil N. Nitrogen mineralization followed a two-pool first- and zero-order kinetic model during the incubations. More than $80 \%$ of the variation in the size of a rapidly mineralizable $\mathrm{N}$ pool $\left(\mathrm{N}_{1}\right)$ was explained by soil organic C. However, stepwise regressions using whole soil variables explained only $27 \%$ of the variation in the rate constant for the rapidly mineralizable $\mathbf{N}$ pool and $36 \%$ of the variation in the rate constant for a slower steady-state phase. Prediction of the two rate constants was improved to 64 and $75 \%$, respectively, and of $N_{1}$ to $97 \%$ by including MHA and CaHA properties in the stepwise regressions. All three mineralization parameters were negatively correlated with the degree of humification in these humic fractions. The degree of humification was positively associated with exchangeable polyvalent cations $\left(\mathrm{Ca}^{+2}\right.$ and $\left.\mathrm{Mg}^{+2}\right)$ and negatively associated with exchangeable $\mathrm{K}^{+}$, suggesting an influence of exchangeable cations on the turnover of young organic matter. We conclude that better understanding the contribution of these humic fractions to short-term $\mathbf{N}$ cycling will improve our ability to predict $\mathrm{N}$ supply in lowland rice soils.
\end{abstract}

A SUBSTANTIAL PROPORTION of $\mathrm{N}$ taken up by crops is derived from mineralization of soil organic matter (SOM). Although reliable prediction of $\mathrm{N}$ mineralization rates would enable more efficient use of $\mathrm{N}$ fertilizer while ensuring an adequate crop $\mathrm{N}$ supply, development of accurate prediction methods has proven to be an elusive goal. For example, total soil $\mathrm{N}$ has been shown to be a poor predictor of actual soil $\mathrm{N}$ availability to the rice crop in irrigated lowland rice systems of the tropics (Cassman et al., 1996a).

One approach to investigating soil $\mathrm{N}$ mineralization has been to extract labile SOM fractions, quantify their relative contributions to $\mathrm{N}$ mineralization, and validate these contributions under field conditions. A number of soil fractionations have been evaluated, including those based on particle size (Christensen, 1992), aggregation (Feller and Beare, 1997), and densitometry

B.V. Nguyen, Dep. of Crop Sciences, Can Tho Univ., Can Tho, Vietnam; D.C. Olk, USDA-ARS, National Soil Tilth Laboratory, 2150 Pammel Dr., Ames, IA 50011; K.G. Cassman, Dep. of Agronomy and Horticulture, Univ. of Nebraska, Lincoln, NE 68583-0915. Journal Series No. 14347 from the Agricultural Research Division, Univ. of Nebraska. AReceived 22 Nov. 2003. *Corresponding author (olk@nstl.gov).

Published in Soil Sci. Soc. Am. J. 68:1266-1277 (2004).

(C) Soil Science Society of America

677 S. Segoe Rd., Madison, WI 53711 USA
(Boone, 1994). Despite these efforts, no single fractionation method has been shown to cleanly distinguish SOM fractions based on their contributions to soil $\mathrm{N}$ mineralization across a wide range of soil types and environments. Organic matter has a rich diversity of organic subunits and bond types, which are apparently arranged in random patterns (MacCarthy, 2001), so it is possible that no single fractionation method can adequately distinguish labile SOM from recalcitrant SOM in all soils.

Whether chemical extractions of SOM can provide fractions that differ clearly in their turnover rates and contributions to nutrient cycling has been questioned by several scientists (Ladd et al., 1977; Cadisch et al., 1996). Yet stabilization of SOM by chemical agents is well known and seems likely to influence the cycling of SOM-bound nutrients. The longevity of chemically stabilized SOM (Jenkinson and Rayner, 1977; Campbell et al., 1967) has been attributed to binding with exchangeable or structural cations (Martin and Haider, 1986; Anderson, 1979), most commonly $\mathrm{Ca}^{+2}, \mathrm{Fe}^{+3}$, and $\mathrm{Al}^{+3}$. Calcium in particular has been found to stabilize organic materials against microbial degradation under laboratory, greenhouse, and field conditions (Baldock and Skjemstad, 2000; Bruckert et al., 1994; Kononova, 1961).

Accordingly, in some SOM studies soil was extracted first with $\mathrm{NaOH}$ to recover the more loosely bound MHA fraction, and then acid-washed to displace polyvalent cations before a second $\mathrm{NaOH}$ extraction to recover the CaHA fraction. Carbon-14 dating found the CaHA fraction to be older than the MHA and in cases considerably older (Campbell et al., 1967; Olk et al., 1995, 1996). In studies of tropical lowland rice soils, the MHA was less humified than the CaHA in its chemical forms of C (Olk et al., 1995, 1996, 1998), N (Mahieu et al., 2000a), and $\mathrm{P}$ (Mahieu et al., 2000b), and in the concentrations of phenolic moieties, functional groups, and free radicals associated with humification (Olk et al., 1999, 2000). Changes in recent crop management regime that resulted in increased SOM content caused a greater proportional increase in the content of MHA than CaHA, and both fractions increased more than did total soil $\mathrm{C}$ or $\mathrm{N}$ (Olk et al., 1996, 1998). During one season in a lowland rice field, ${ }^{15} \mathrm{~N}$-labeled urea $\mathrm{N}$ cycled into and out of the MHA and CaHA faster than for bulk SOM (Olk and Cassman, 2002). Similar trends in N cycling were found in California rice soils by Devêvre and Horwath (2001) and Bird et al. (2003), who also fractionated

Abbreviations: BIARC, Bicol Integrated Agricultural Research Center; CaHA, calcium humates; $\mathrm{E}_{4}$, optical density at $465 \mathrm{~nm}$; HA, humic acid; IRRI, International Rice Research Institute; LTFE, Long-Term Fertility Experiment; MHA, mobile humic acids; PhilRice, Philippine Rice Research Institute Research; SOM, soil organic matter. 
humic material based on binding to polyvalent cations. Taken together, these studies of chemical structure, age, and accumulation of MHA and CaHA in rice soils, and the fact that they represented a substantial pool of organic $\mathrm{N}$ ranging from 13 to $23 \%$ of total soil $\mathrm{N}$ (Olk et al., 1996, 1998), suggest these fractions are likely to have a large impact on $\mathrm{N}$ mineralization rates in lowland rice soils.

Accurate prediction of $\mathrm{N}$ mineralization would be especially useful for managing irrigated lowland rice. A high-yielding rice crop takes up 150 to $200 \mathrm{~kg} \mathrm{~N}^{-1}$ and soil $\mathrm{N}$ mineralization accounts for at least half of this amount (Cassman et al., 1996b). Under the conventional annual system of double- or triple-cropping of lowland rice in irrigated areas of tropical and subtropical Asia, the continually flooded soil conditions limit the abundance of inorganic $\mathrm{N}$ in the soil-floodwater system because nitrification is inhibited under anoxic conditions and ammonium can be rapidly lost to volatilization (Buresh and De Datta, 1990). Consequently, crop growth in the late season after panicle initiation is largely dependent on soil $\mathrm{N}$ mineralization unless $\mathrm{N}$ fertilizer is applied in several split applications, which is not a common practice. Despite the substantial contribution of soil $\mathrm{N}$ mineralization to $\mathrm{N}$ uptake by rice and the wide ranges in soil $\mathrm{N}$ supply measured under field conditions, soil $\mathrm{N}$ supply is not well correlated with SOM levels in lowland rice soils (Cassman et al., 1996a). If the soil $\mathrm{N}$ supply is instead more closely associated with labile SOM fractions, chemical extraction of these labile fractions might provide useful information about $\mathrm{N}$ mineralization potential and seasonal dynamics. Because lowland rice soils undergo a puddling operation before each cropping period that destroys soil aggregation, the importance of physical processes that stabilize SOM in aerated soils are perhaps less important in these lowland soils.

The primary objective of this study was to determine whether the prediction of soil $\mathrm{N}$ mineralization could be improved by considering the properties of chemically extracted humic fractions. Specifically, properties and quantities of the MHA and CaHA fractions, combined with the more commonly evaluated properties of whole soil, were used to predict $\mathrm{N}$ mineralization during 84-d anaerobic incubations of soils from Vietnam and the Philippines. The soils were sampled from fields that had been under continuous double- and triple-cropping with rice. Secondary objectives of this study were to (i) establish whether sampled soil can be air-dried without altering properties of subsequently extracted humic acid (HA) fractions, and (ii) determine whether the amounts and chemical properties of the extracted HA fractions were associated with other soil properties.

\section{MATERIALS AND METHODS}

\section{Soil Location and Sampling}

\section{Effect of Soil Air-drying on MHA and CaHA Extraction}

Soil was sampled from the Long-Term Fertility Experiment (LTFE), which was conducted at three research stations in
Luzon, Philippines: the Bicol Integrated Agricultural Regional Center (BIARC), the International Rice Research Institute (IRRI), and the Philippine Rice Research Institute (PhilRice). Soils were Typic Pelludert, Andaqueptic Haplaquoll, and Vertic Tropaquept, respectively. At each site a common set of replicated nutrient management treatments has been applied to a continuous annual double-cropped rotation of irrigated lowland rice for more than $20 \mathrm{yr}$ (Cassman et al., 1995). The field layout of the LTFE is a factorial randomized complete block, with three rice varieties arranged in combination with $\mathrm{N}, \mathrm{P}$, and $\mathrm{K}$ fertilizer treatments, which included one treatment with a full complement of $\mathrm{N}, \mathrm{P}$, and $\mathrm{K}$ at recommended rates, a control treatment without applied nutrients, and various partial combinations of N, P, and K input. Soil was sampled from the 0 - to $15-\mathrm{cm}$ depth of selected treatments at each site in the 1994 dry season, one month after transplanting. Each soil sample was a composite of the varietal plots for a given fertilizer treatment in one block. The IRRI site had four blocks, and the BIARC and PhilRice sites had three blocks each.

One portion of each soil sample was stored in glass bottles which were filled with water, capped tightly to avoid oxidation, and kept under refrigeration at $4^{\circ} \mathrm{C}$ until $\mathrm{HA}$ extraction. These subsamples will be referred to as "fresh soils." The remaining portion of each soil was spread before a fan to achieve rapid drying in about $2 \mathrm{~d}$ at room temperature. Oxidized Fe compounds did not accumulate on the exterior of the clods, suggesting minimal activity by aerobic microorganisms. A portion of each air-dried soil was ground to pass through a 2-mm sieve for HA extraction. These soils will be referred to as "predried soils." The remaining air-dried soil was used for measurement of other soil properties.

\section{Correlations among Properties of Humic Fractions and Whole Soil}

Fourteen soils were sampled, including nine farmers' fields in Vietnam, one farmer's field in Central Luzon, Philippines, each of the three LTFE sites, and a long-term fertility experiment in Vietnam. A humid tropical climate prevailed at all sites, with a distinct wet season and a dry season. The soils in the farmers' fields had not been classified following the U.S. taxonomy, but they were typical of the major irrigated lowland rice-producing regions of Vietnam and the Philippines. All fields had been in a continuous annual rotation of double- or triple-cropped irrigated lowland rice for many years, and all soils had formed in alluvial sediment. Eight Vietnamese fields were located in various landforms of the Mekong Delta, the major rice-producing region in Vietnam. Two farmers' fields were from the Hue region in central Vietnam. Field size was relatively small, ranging from 2000 to 4000 $\mathrm{m}^{2}$, and soil samples were taken at three locations within each field. Location replicates within fields were extracted separately for HA fractions but were bulked into composites for each field for all other soil analyses. Samples were taken from the 0- to $15-\mathrm{cm}$ depth at the beginning of the 1992 wet season for the Philippine farmer and the beginning of the 1995 dry season for the Vietnamese fields. The LTFE samples were collected from the 0 - to $20-\mathrm{cm}$ depth. A composite soil was made for each block at each site from the three varietal plots.

All sampled soils were rapidly air-dried under a fan and ground to pass through a 2-mm sieve. One subsample of each dried soil was used for HA extraction and another for determination of soil properties.

\section{Correlation of Humic Fraction Properties with Soil Nitrogen Mineralization}

The air-dried composites for 12 of the 14 soils (Tanhoi and Thotnot soils were excluded because their amounts were 
inadequate) were subsampled and ground to pass through a 1-mm sieve for soil $\mathrm{N}$ mineralization incubations.

\section{Measurement of Soil Properties}

Soil organic C was measured by a modified Walkley-Black procedure (Nelson and Sommers, 1975). Soil $\mathrm{pH}$ was measured in a slurry having a soil/water ratio of 1:2.5 (w/v). Soil exchangeable $\mathrm{Ca}, \mathrm{Mg}, \mathrm{K}$, and $\mathrm{Na}$ were determined through extraction by $1 M$ ammonium acetate and analysis by atomic absorption spectroscopy, and soil cation-exchange capacity was determined through subsequent extraction of $\mathrm{NH}_{4}$ by a $1 \mathrm{M} \mathrm{KCl}$ solution adjusted to $\mathrm{pH} 2.5$, and colorimetric determination (Great Britain Ministry of Agriculture, Fisheries, and Food, 1981). Particle-size analysis was performed by the pipette method (Gee and Bauder, 1986). Total soil N was determined by a macro-Kjeldahl method (Stumpe et al., 1985).

\section{Humic Acid Extraction and Characterization}

The MHA and CaHA were extracted from soil following a procedure described by Olk et al. (1996). Briefly, predried soil or fresh soil (18 $\mathrm{g}$ oven-dried basis) was incubated under $\mathrm{N}_{2}$ gas in $180 \mathrm{~mL}$ of $0.25 \mathrm{M} \mathrm{NaOH}$ for $20 \mathrm{~h}$. The solution was centrifuged and the solubilized MHA was decanted and acidified to $\mathrm{pH}$ 1.95. After two washes with $0.0025 \mathrm{M} \mathrm{CaCl}_{2}$ under $\mathrm{N}_{2}$ gas to flocculate fine clays in suspension that had combined with soluble MHA, the soil was decalcified by 0.1 $M \mathrm{HCl}$ washes until the $\mathrm{pH}$ of the supernatant remained below 1.3. The CaHA was subsequently extracted with $0.25 \mathrm{M} \mathrm{NaOH}$ using the same protocol as for the MHA. To reduce inorganic contamination, both the MHA and CaHA were shaken in a $0.5 \%(\mathrm{v} / \mathrm{v}) \mathrm{HF}+0.5 \%(\mathrm{v} / \mathrm{v}) \mathrm{HCl}$ solution for $3 \mathrm{~d}$ with daily solution replacement. The MHA and CaHA were $\mathrm{H}^{+}-$ saturated by dialyzing for $3 \mathrm{~d}$ against $\mathrm{HCl}$ and water solutions. Then the MHA and CaHA were frozen, lyophilized, and stored as a dry powder.

The $\mathrm{C}$ and $\mathrm{N}$ concentrations of the MHA and CaHA were determined by dry combustion on a $\mathrm{CHN}$ automated elemental analyzer. Ash content was determined gravimetrically after heating to $700^{\circ} \mathrm{C}$ for $3 \mathrm{~h}$ and was generally $<1 \%$. All values reported for $\mathrm{C}$ and $\mathrm{N}$ concentration are corrected for ash content. On a whole soil basis, the amounts of $\mathrm{N}$ or $\mathrm{C}$ contained in the extracted MHA (MHA-N or MHA-C) and CaHA (CaHA-N or CaHA-C) were estimated as the products of the $\mathrm{N}$ and $\mathrm{C}$ concentrations of each $\mathrm{HA}$ fraction and their mass extracted per kilogram of soil. The MHA-N fraction of total extracted HA-N was calculated as the ratio of MHA-N to the sum of MHA-N and CaHA-N. The CaHA-N fraction and $\mathrm{C}$ equivalents for both fractions were calculated in a similar manner. The optical densities at $465 \mathrm{~nm}\left(\mathrm{E}_{4}\right)$ and 665 $\mathrm{nm}$ were determined on solutions of $3 \mathrm{mg} \mathrm{HA}-\mathrm{C}$ solubilized in $30 \mathrm{~mL}$ of $0.05 \mathrm{M} \mathrm{NaHCO}_{3}$ (Chen et al., 1977). Only the $\mathrm{E}_{4}$ data are reported here: optical density at $665 \mathrm{~nm}$ provided similar information but was a less sensitive parameter. Across several rice soils, the $\mathrm{E}_{4}$ values were found to be highly correlated with other chemical properties of the MHA and CaHA, including free radical concentration (Olk et al., 2000) and spectral area proportions for most $\mathrm{C}, \mathrm{N}$, and $\mathrm{P}$ functional groups determined by nuclear magnetic resonance spectroscopy (Mahieu et al., 2002). In all cases, the $\mathrm{E}_{4}$ values increased with increasing degree of humification, confirming similar observations in earlier studies (Schnitzer and Lévesque, 1979).

\section{In Vitro Soil Nitrogen Mineralization}

A modified anaerobic incubation was used as described by Saeed (1995). Briefly, $2 \mathrm{~g}$ of air-dried soil and then $1 \mathrm{~g}$ of dry cation-exchange resin beads saturated with $\mathrm{K}^{+}$were placed in 20-mL glass test tubes and mixed. Fifteen milliliters of deionized water was added to each tube. The tubes were then flushed with $\mathrm{N}_{2}+5(\mathrm{v} / \mathrm{v}) \% \mathrm{CO}_{2}$ gas for $20 \mathrm{~s}$ at a flow rate of $2.5 \mathrm{~mL} \mathrm{~s}^{-1}$ and stoppered immediately. Duplicate samples were incubated at $30^{\circ} \mathrm{C}$ for $0,7,14,28,42,63$, and $84 \mathrm{~d}$, a period comparable with the 95 - to 100 -d duration of a tropical lowland rice crop.

The $\mathrm{K}^{+}$-saturated resin likely reduces volatilization losses of solution $\mathrm{NH}_{4}^{+}$through rapid adsorption of mineralized $\mathrm{NH}_{4}^{+}$, and it prevents $\mathrm{NH}_{4}^{+}$loss to mineral fixation through $\mathrm{K}^{+}$-saturation of clay mineral interlayers. These features allow for increased recovery of mineralized $\mathrm{N}$, especially during incubations of long duration and high mineralization rates. Compared with some field situations, however, this method may overestimate the amount of mineralized $\mathrm{N}$ that would become bio-available, especially during growth stages with lower rates of crop $\mathrm{N}$ uptake.

At each extraction time, the contents of each tube were quantitatively transferred to a 50-mL centrifuge tube via three 5-mL rinses with $4 \mathrm{M} \mathrm{KCl}$. The combined solution was shaken at $180 \mathrm{rpm}$ for $30 \mathrm{~min}$ and centrifuged at $17000 \times g$ for 10 $\min$. The supernatant solution was passed through filter paper into a plastic bottle and acidified with four drops of $\mathrm{HCl} / \mathrm{H}_{2} \mathrm{O}$ (1:1) solution. Because the soil residue in the centrifuge bottle typically contained measurable amounts of extractable $\mathrm{NH}_{4}$ (Saeed, 1995), another $20 \mathrm{~mL}$ of $2 \mathrm{M} \mathrm{KCl}$ was added to the soil residue for a second extraction, following the same protocol for the first extraction. The $\mathrm{NH}_{4}-\mathrm{N}$ concentration in each extract was determined spectrophotometrically (Kempers and Zweers, 1986) and summed for both soil washes.

\section{Statistical and Regression Analysis}

Simple correlation and stepwise regressions were performed to evaluate the influence of soil properties on MHA and $\mathrm{CaHA}$ properties and quantities. Unless otherwise indicated, significance was defined at the level of $P<0.05$ throughout this study. Twelve soil properties (soil organic C, total soil $\mathrm{N}$, soil $\mathrm{C} / \mathrm{N}$ ratio, $\mathrm{pH}$, cation-exchange capacity, exchangeable $\mathrm{Ca}, \mathrm{Mg}, \mathrm{K}$, and $\mathrm{Na}$, and percentage of clay, silt, and sand) were used as independent variables in regression using the stepwise procedure (SAS Institute, 1990) to predict the quantity ( $\mathrm{C}$ and $\mathrm{N}$ contents) and quality $\left(\mathrm{E}_{4}\right.$ and $\mathrm{C} / \mathrm{N}$ ratio) of MHA and CaHA. Independent variables entered the model at a significance level $<0.15$.

A two-pool first- and zero-order model as described by Cabrera (1993) and Saeed (1995) was used to fit an equation to net extractable $\mathrm{NH}_{4}-\mathrm{N}$ during the anaerobic incubation of each soil, where net extractable $\mathrm{NH}_{4}-\mathrm{N}$ is defined as the increase in extracted $\mathrm{NH}_{4}-\mathrm{N}$ from the beginning of the incubation to each sampling time. The model has the following form:

$$
N_{\mathrm{t}}=N_{1}\left[1-\exp \left(-k_{1} t\right)\right]+k_{2} t
$$

The $N_{t}$ term represents net extractable $\mathrm{NH}_{4}-\mathrm{N}$ at time $t, N_{1}$ is the total size of an initially available, rapidly mineralizable $\mathrm{N}$ pool, $k_{1}$ is the rate constant for this rapid phase of $\mathrm{N}$ mineralization, and $k_{2}$ is the rate constant for a subsequent slower phase of steady-state $\mathrm{N}$ mineralization.

Stepwise regression (SAS Institute, 1990) was used to identify which properties of whole soil and the MHA and CaHA fractions had the greatest influence on the mineralization parameters of the two-pool model. Independent variables entered the model at a significance level of 0.15 . Because of the high colinearity between soil organic $\mathrm{C}$ and total soil $\mathrm{N}$, one of these two properties was included as an independent variable in each preliminary stepwise regression, but not both 
properties together. Soil organic $\mathrm{C}$ provided the higher partial coefficients of determination for $N_{1}$, so total soil $\mathrm{N}$ was excluded from subsequent regressions for $N_{1}$. A squared term for soil organic $\mathrm{C}$ was also included in subsequent regressions for $N_{1}$ because of an apparent curvilinear relationship between soil organic $\mathrm{C}$ and $N_{1}$. Total soil $\mathrm{N}$ provided the higher partial coefficients of determination for $k_{1}$ and $k_{2}$, so soil organic $\mathrm{C}$ and its squared term were excluded from subsequent regressions for these parameters.

The selected regression models were confirmed through the maximum $R^{2}$ improvement technique using the MAXR procedure (SAS Institute, 1990). A few regression models identified by stepwise analysis were replaced by MAXR results when the $R^{2}$ value increased substantially, Akaike's information criterion value (Shumway, 1988) did not increase substantially, and colinearity among the selected independent variables was not substantially worsened, based on multiple diagnostics including guidelines recommended by Freund and Littell (1991).

Four main groups of independent variables were used separately for prediction of the three mineralization parameters:

Model 1-Whole soil properties: soil organic C, total soil N, $\mathrm{C} / \mathrm{N}$ ratio, $\mathrm{pH}$, exchangeable $\mathrm{Ca}$, and exchangeable $\mathrm{K}$.

Model 2-Soil properties of Model 1 plus properties of the MHA: MHA-C, MHA-N, C/N ratio of MHA (MHA-C/N), $\mathrm{E}_{4}$ of MHA (MHA- $\mathrm{E}_{4}$ ), and the ratio of $\mathrm{N}$ extracted as MHA to the sum of $\mathrm{N}$ extracted as MHA and CaHA (MHA-N fraction).

Model 3-Soil properties of Model 1 plus properties of the CaHA: MHA-N fraction, CaHA-C, CaHA-N, CaHA-C/N, and $\mathrm{CaHA}-\mathrm{E}_{4}$

Model 4-All soil, MHA, and CaHA properties listed in Models 1 through 3 .

Two additional multiple regressions evaluated the MHA properties alone and the CaHA properties alone as independent variables and the mineralization parameters of the two-pool model as dependent variables.

\section{RESULTS}

\section{Effect of Soil Air-Drying on MHA and CaHA Extraction}

The amount of N extracted as MHA or CaHA differed little between fresh and predried soil from the

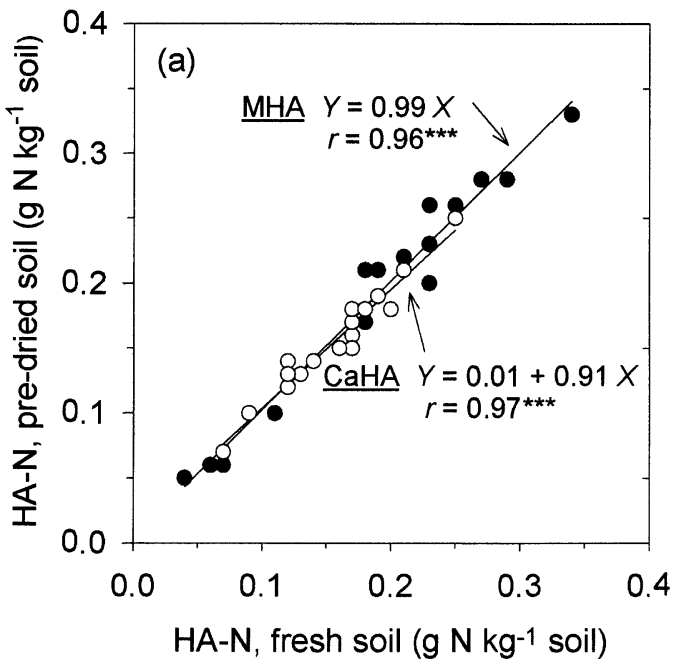

treatments sampled at the LTFE sites (Fig. 1a). Previous soil drying also had little effect on the $\mathrm{C}$ and $\mathrm{N}$ concentrations of the HA fractions (data not shown) or their $\mathrm{C} / \mathrm{N}$ ratios (Fig. 1b). These results were similar across all three LTFE sites, despite substantial differences in soil organic $\mathrm{C}$, total soil $\mathrm{N}$, other soil properties (Table 1 ), and parent material. Consequently, all HA fractions used for chemical analysis and for regression with the incubation studies on $\mathrm{N}$ mineralization were obtained from soil that had been rapidly air-dried.

\section{Properties of Whole Soil and Extracted Humic Fractions}

Clay content varied from 150 to $680 \mathrm{~g} \mathrm{~kg}^{-1}$ soil and silt content from 300 to $670 \mathrm{~g} \mathrm{~kg}^{-1}$ soil. The Vietnamese soils varied from slightly acidic to acidic reaction, while the Philippine soils were nearly neutral (Table 1). Cation-exchange capacity and exchangeable $\mathrm{Ca}$ and $\mathrm{Mg}$ of the Vietnamese soils were less than for most Philippine soils. The $\mathrm{C}$ contents of these soils represent moderate to high levels that are typical of irrigated lowland rice soils in Southeast Asia (Kawaguchi and Kyuma, 1977). Soil organic $\mathrm{C}$ and total soil $\mathrm{N}$ were highly correlated $(r=0.97, P<0.001)$, indicating a relatively consistent $\mathrm{C} / \mathrm{N}$ ratio of $10.8 \pm 0.9$ across soils.

The amounts of $\mathrm{C}$ and $\mathrm{N}$ extracted from the soils as $\mathrm{HA}$ varied considerably more than did total organic $\mathrm{C}$ and total soil N. Soil organic $\mathrm{C}$ and total soil $\mathrm{N}$ varied by a factor of $2.7(\mathrm{C})$ to $3.0(\mathrm{~N})$ across the 14 soils, which compares with 21-fold and 9-fold differences for MHA-N and CaHA-N, respectively (Tables 1 and 2). Amounts of MHA-N and CaHA-N varied significantly among the 14 soils, ranging from 0.022 to $0.464 \mathrm{~g} \mathrm{~kg}^{-1}$ soil for the MHA-N and from 0.050 to $0.432 \mathrm{~g} \mathrm{~kg}^{-1}$ soil for the CaHA-N (Table 2). The coefficients of variation across soils were about $60 \%$ for the $\mathrm{N}$ contents of both fractions. Combined, the MHA-N and CaHA-N represented 15 to $30 \%$ of total soil $\mathrm{N}$, but the proportions of total soil $\mathrm{N}$ contained in each $\mathrm{HA}$ fraction differed

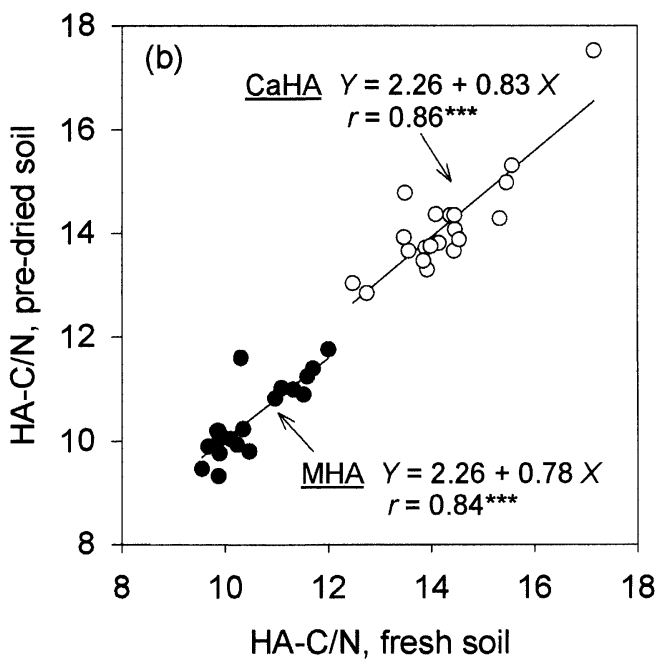

Fig. 1. The relationships between properties of humic acids (HA) extracted from predried soil versus fresh soil for the 0- to 15-cm depth of two fertilizer treatments at three sites of the Long-Term Fertility Experiment: (a) amount of $\mathbf{N}$ extracted as HA (HA-N), and (b) C/N ratio of HA (HA-C/N). The mobile humic acid fraction is the MHA, and the calcium humate fraction is the CaHA. Each data point represents one field replicate of a fertilizer treatment at each site. 
Table 1. Properties of 14 tropical lowland rice soils for the 0 - to $15-\mathrm{cm}$ depth.

\begin{tabular}{|c|c|c|c|c|c|c|c|c|c|}
\hline \multirow[b]{2}{*}{ Soil } & \multirow{2}{*}{$\begin{array}{c}\text { Soil } \\
\text { organic C }\end{array}$} & \multirow{2}{*}{$\begin{array}{c}\text { Clay } \\
\text { content }\end{array}$} & \multirow{2}{*}{$\begin{array}{c}\text { Silt } \\
\text { content }\end{array}$} & \multirow[b]{2}{*}{ pH } & \multirow{2}{*}{$\begin{array}{l}\text { Cation exchange } \\
\text { capacity }\end{array}$} & \multicolumn{4}{|c|}{ Exchangeable cations } \\
\hline & & & & & & Ca & Mg & $\mathbf{K}$ & $\mathbf{N a}$ \\
\hline & & $\mathrm{kg}^{-1}$ soil & 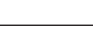 & & . & $-\mathrm{cmo}$ & soil - & & \\
\hline Binhduc $\dagger$ & 15.7 & 450 & 545 & 5.4 & 13.2 & 7.6 & 2.3 & 0.26 & 0.19 \\
\hline Cantho $\dagger$ & 26.4 & 445 & 545 & 5.3 & 15.9 & 9.3 & 2.8 & 0.24 & 0.28 \\
\hline Huongso $\dagger$ & 14.1 & 200 & 530 & 6.3 & 4.2 & 2.3 & 1.5 & 0.09 & 0.50 \\
\hline Longhiep $\dagger$ & 13.6 & 560 & 425 & 4.6 & 19.9 & 5.1 & 8.2 & 0.21 & 0.93 \\
\hline Myyen $\dagger$ & 14.7 & 635 & 345 & 4.7 & 23.2 & 6.1 & 8.7 & 0.29 & 0.55 \\
\hline Tambinh $\dagger$ & 19.6 & 550 & 440 & 6.3 & 14.0 & 8.9 & 6.7 & 0.17 & 0.64 \\
\hline Tanhoi $\nmid$ & 21.2 & 680 & 300 & 6.0 & 22.6 & 10.8 & 10.7 & 0.36 & 1.13 \\
\hline Thotnot $\dagger$ & 16.7 & 320 & 670 & 5.3 & 11.2 & 7.1 & 1.9 & 0.12 & 0.19 \\
\hline Thuybang $\dagger$ & 14.7 & 150 & 590 & 5.3 & 2.4 & 1.0 & 0.2 & 0.07 & 0.05 \\
\hline Cuulong & 32.6 & 560 & 436 & 5.5 & 22.0 & 11.1 & 8.1 & 0.23 & 0.48 \\
\hline Guimba§ & 12.1 & 360 & 430 & 7.7 & 27.1 & 18.8 & 12.3 & 0.10 & 0.56 \\
\hline BIARCII & 23.1 & 525 & 345 & 7.0 & 29.7 & 18.0 & 10.1 & 0.51 & 2.09 \\
\hline IRRI|] & 22.0 & $\mathbf{5 5 0}$ & 355 & 6.5 & 35.7 & 18.2 & 11.8 & 1.51 & 1.44 \\
\hline PhilRiceII & 15.5 & 400 & 505 & 6.6 & 25.4 & 18.0 & 8.4 & 0.11 & 0.56 \\
\hline
\end{tabular}

$\uparrow$ Soils were sampled from farmers' fields in the Mekong Delta and Hue region of Vietnam.

† Soil was sampled from the Cuu Long Delta Rice Research Institute in the Mekong Delta of Vietnam.

$\S$ Soil was sampled from a farmer's field in central Luzon, Philippines.

II Soils were sampled from three rice research stations in Luzon, Philippines.

greatly among soils. In the Cantho, Huongso, Longhiep, and Thuybang soils, the MHA accounted for more than $70 \%$ of the $\mathrm{N}$ in the extracted HA, but only 15 to $37 \%$ in the Guimba and PhilRice soils.

The amount of HA-C in each soil closely followed trends in the amount of HA-N, as the coefficient of determination was 0.99 for these two variables across the 14 soils for both HA fractions (data not shown). The MHA-C varied from 0.21 to $5.00 \mathrm{~g} \mathrm{~kg}^{-1}$ soil and the CaHA-C varied from 0.56 to $5.02 \mathrm{~g} \mathrm{~kg}^{-1}$ soil. The coefficients of variation in HA-C across soils exceeded $50 \%$. Combined, the MHA-C and CaHA-C represented 17 to $30 \%$ of soil organic $\mathrm{C}$.

Humic quality also varied across sites, if somewhat less than did humic quantity. Although the C concentration of each HA fraction was relatively constant across soils, the $\mathrm{N}$ concentration was more variable, especially in the CaHA (Table 3). As a result, the $\mathrm{C} / \mathrm{N}$ ratio ranged from 9.1 to 11.5 in the MHA and from 9.4 to 16.1 in the CaHA. Across all soils, the MHA had a lower $(P<$ $0.01) \mathrm{C}$ concentration and $\mathrm{C} / \mathrm{N}$ ratio and higher $\mathrm{N}$ concentration than the CaHA. These results agree with previous chemical characterizations of these HA fractions (Olk et al., 1995, 1996, 1998).

In all soils the MHA- $\mathrm{E}_{4}$ was smaller than the $\mathrm{CaHA}-\mathrm{E}_{4}$, indicating the CaHA was more humified (Mahieu et al., 2002). The colors of the MHA and CaHA varied among soils. For example, the color of the MHA in the dry powder state was brown (7.5YR 3/5 by the Munsell Color Chart) for the Guimba soil, dark reddish-brown (5YR 3/3) for the BIARC soil, and reddish-black (2.5YR 2/1) for the Cuulong soil. In all soils, the CaHA fraction was darker than the MHA fraction. With increasing humification, the color of the HA typically darkens from yellowish-brown to brown to nearly black (Kumada, 1987), again indicating a more humified state of the CaHA compared with the MHA.

Table 2. The amount of $N$ in the mobile humic acid (MHA) and the calcium humate (CaHA) fractions extracted from the 0- to 15-cm depth of 14 tropical lowland rice soils.

\begin{tabular}{|c|c|c|c|c|c|c|c|}
\hline \multirow[b]{2}{*}{ Soil } & \multicolumn{3}{|c|}{ Nitrogen content } & \multicolumn{2}{|c|}{ Proportion of total soil $\mathbf{N}$} & \multicolumn{2}{|c|}{ Fraction of humic acid-N } \\
\hline & $\begin{array}{c}\text { Whole } \\
\text { soil }\end{array}$ & MHA & CaHA & МHА & CaHA & МНА & CaHA \\
\hline & & $\mathrm{g} \mathrm{kg}^{-1} \mathrm{~s}$ & 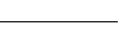 & $\longrightarrow$ & 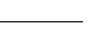 & & \\
\hline Binhduc & 1.63 & 0.155 & $0.122 * *$ & 9.5 & 7.5 & 0.56 & 0.44 \\
\hline Cantho & 2.34 & 0.451 & $0.184 * * *$ & 19.3 & 7.9 & 0.71 & 0.29 \\
\hline Huongso & 1.36 & 0.212 & $0.085 * * *$ & 15.6 & 6.2 & 0.71 & 0.29 \\
\hline Longhiep & 1.35 & 0.158 & $0.064 * *$ & 11.7 & 4.7 & 0.71 & 0.29 \\
\hline Myyen & 1.46 & 0.177 & $0.098 * * *$ & 12.1 & 6.7 & 0.64 & 0.36 \\
\hline Tambinh & 1.89 & 0.222 & $0.177^{n s} \uparrow$ & 11.7 & 9.3 & 0.56 & 0.44 \\
\hline Tanhoi & 2.09 & 0.178 & $0.167 *$ & 8.5 & 8.0 & 0.52 & 0.48 \\
\hline Thotnot & 1.62 & 0.175 & 0.117** & 10.8 & 7.2 & 0.60 & 0.40 \\
\hline Thuybang & 1.49 & 0.291 & $\mathbf{0 . 0 5 0} * * *$ & 19.5 & 3.4 & 0.85 & 0.15 \\
\hline Cuulong & 2.96 & 0.464 & 0.432 ns & 15.7 & 14.6 & 0.52 & 0.48 \\
\hline Guimba & 1.00 & 0.022 & $0.130 * * *$ & 2.2 & 13.0 & 0.15 & 0.85 \\
\hline BIARC & 1.96 & 0.181 & 0.202 ns & 9.2 & 10.3 & 0.47 & 0.53 \\
\hline IRRI & 1.84 & 0.213 & $0.155 * * *$ & 11.6 & 8.4 & 0.58 & 0.42 \\
\hline PhilRice & 1.25 & 0.074 & $0.124 * * *$ & 5.9 & 9.9 & 0.37 & 0.63 \\
\hline Mean & 1.73 & 0.212 & 0.151 & 11.7 & 8.4 & 0.57 & 0.43 \\
\hline CV, \% & 29 & 58 & 62 & 41 & 36 & 30 & 39 \\
\hline
\end{tabular}

* Significant differences at the 0.05 probability level between MHA-N and CaHA-N for each soil.

** Significant differences at the 0.01 probability level between MHA-N and CaHA-N for each soil.

*** Significant differences at the 0.001 probability level between MHA-N and CaHA-N for each soil.

$\dagger$ Not significant. 
Table 3. Elemental composition and optical density (OD) at $465 \mathrm{~nm}\left(\mathrm{E}_{4}\right)$ for the mobile humic acid (MHA) and calcium humate (CaHA) fractions extracted from the $0-$ to $15-\mathrm{cm}$ depth of 14 tropical lowland rice soils. $\dagger$

\begin{tabular}{|c|c|c|c|c|c|c|c|c|}
\hline \multirow[b]{2}{*}{ Soil } & \multicolumn{2}{|c|}{$\mathrm{C}$ concentration } & \multicolumn{2}{|c|}{$\mathbf{N}$ concentration } & \multicolumn{2}{|c|}{$\mathrm{C} / \mathrm{N}$ ratio } & \multicolumn{2}{|c|}{$\mathbf{E}_{4}$} \\
\hline & МНА & CaHA & МНА & CaHA & МНА & CaHA & МНА & CaHA \\
\hline & \multicolumn{4}{|c|}{$\longrightarrow \mathrm{g} \mathrm{kg}^{-1}$ humic acid $\longrightarrow$} & & & \multicolumn{2}{|c|}{ — OD units (g HA-C $\mathbf{L}^{-1}$ solution) $)^{-1}$} \\
\hline Binhduc & 544 & 561 & 52.6 & 41.9 & $\mathbf{1 0 . 3}$ & 13.4 & $\mathbf{5 . 1 0}$ & 11.8 \\
\hline Cantho & 546 & 564 & 49.8 & 42.8 & 11.0 & 13.2 & 5.21 & 11.0 \\
\hline Huongso & 526 & 529 & 54.2 & 48.6 & 9.7 & 10.9 & 3.36 & 8.1 \\
\hline Longhiep & 551 & 555 & 49.5 & 45.2 & 11.1 & 12.3 & 6.09 & 11.8 \\
\hline Myyen & 548 & 565 & 51.8 & 43.0 & 10.6 & 13.2 & 6.62 & 14.5 \\
\hline Tambinh & 540 & 553 & 56.3 & 46.8 & 9.6 & 11.8 & 3.04 & 9.1 \\
\hline Tanhoi & 540 & 554 & 53.7 & 43.7 & 10.0 & 12.7 & 3.62 & 10.7 \\
\hline Thotnot & 523 & 542 & 52.6 & 42.6 & 9.9 & 12.7 & 4.42 & 11.5 \\
\hline Thuybang & 525 & 530 & 57.8 & 56.4 & 9.1 & 9.4 & 4.62 & 5.1 \\
\hline Cuulong & 542 & 573 & 52.1 & 51.4 & 10.4 & 11.2 & 7.77 & 16.6 \\
\hline Guimba & 538 & 575 & 57.5 & 35.7 & 9.4 & 16.1 & 2.05 & 13.3 \\
\hline BIARC & 533 & 544 & 55.2 & 40.7 & 9.7 & 13.4 & 3.51 & 12.0 \\
\hline IRRI & 539 & 552 & 47.0 & 40.0 & 11.5 & 13.8 & 3.58 & 9.8 \\
\hline PhilRice & 541 & 554 & 53.3 & 37.3 & 10.2 & 14.9 & 2.24 & 10.0 \\
\hline Mean & 538 & 554 & 53.1 & 44.0 & 10.2 & 12.8 & 4.37 & 11.1 \\
\hline CV, \% & 2 & 2 & 6 & 12 & 7 & 13 & 38 & 25 \\
\hline Difference $\ddagger$ & \multicolumn{2}{|c|}{$16 * *$} & \multicolumn{2}{|c|}{$9.1 * *$} & \multicolumn{2}{|c|}{$2.6^{* *}$} & \multicolumn{2}{|c|}{$6.7 * *$} \\
\hline
\end{tabular}

** Significant differences at the 0.01 probability level.

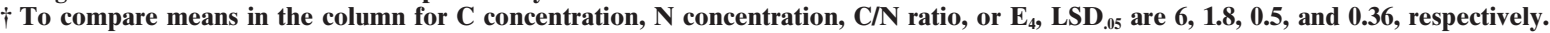

+ Difference between overall means of MHA and CaHA.

\section{Correlations among Properties of Humic Fractions and Whole Soil}

The amounts of $\mathrm{N}$ extracted as MHA and CaHA were strongly correlated $(P<0.001)$ with total soil $\mathrm{N}$ (Table 4) and soil organic $\mathrm{C}$ (data not shown). Soil organic $\mathrm{C}$ and total soil $\mathrm{N}$ explained 61 to $79 \%$ of the variation of the HA-N (Fig. 2) and 62 to $74 \%$ variation in the HA-C (data not shown). The amounts of MHA-N and CaHA-N were not correlated with any other properties of whole soil measured in this study (Table 4). There was a strong negative correlation between the proportion of total HA-N found in the MHA (MHA-N fraction) and exchangeable $\mathrm{Ca}(P<0.001)$, exchangeable $\mathrm{Mg}$, and soil $\mathrm{pH}(P<0.01)$.

Of the SOM quality variables, the $\mathrm{E}_{4}$ of either $\mathrm{HA}$ fraction was positively correlated with the $\mathrm{N}$ content of that fraction (Table 4). The $\mathrm{CaHA}-\mathrm{C} / \mathrm{N}$ was strongly correlated with exchangeable $\mathrm{Ca}$, and to a lesser degree with exchangeable $\mathrm{Mg}$, soil $\mathrm{pH}$ and cation-exchange capacity (not shown), which were significantly cross-correlated.
Soil organic $\mathrm{C}$, total soil $\mathrm{N}$, and exchangeable cations were also prominent in stepwise regressions for HA quantity and quality properties against all 12 soil properties (data not shown). Prediction of HA-N and-C was improved to 79 to $96 \%$ by including either soil organic $\mathrm{C}$ or total soil $\mathrm{N}$ along with (i) the soil $\mathrm{C} / \mathrm{N}$ ratio and extractable $\mathrm{Ca}$ (MHA-C and -N), or (ii) exchangeable $\mathrm{Mg}$ and $\mathrm{K}$ (CaHA-C only). The MHA-N fraction was significantly explained $\left(R^{2}=0.84\right)$ by exchangeable $\mathrm{Ca}$ (0.67) and exchangeable K (0.17). The divalent $\mathrm{Ca}$ was negatively associated with all MHA quantities (MHA-N fraction, MHA-C, and MHA-N), while conversely the monovalent $\mathrm{K}$ was positively associated with the MHA-N fraction and negatively associated with CaHA-C. In stepwise regression for the SOM quality terms, much of the variation in the MHA-C/N $\left(R^{2}=0.78, P=0.0051\right)$ was explained by exchangeable $\mathrm{K}\left(R^{2}=0.34\right)$ and soil $\mathrm{C} / \mathrm{N}$ ratio $\left(R^{2}=0.15\right)$, and most of the variation in the CaHA-C/N $\left(R^{2}=0.86, P=0.001\right)$ was explained by exchangeable $\mathrm{Ca}\left(R^{2}=0.63\right)$, and soil organic $\mathrm{C}$ $\left(R^{2}=0.14\right)$.

Table 4. Correlation matrix for selected properties of 14 tropical lowland rice soils and their mobile humic acid (MHA) and calcium humate (CaHA) fractions. Soil was sampled from the 0- to 15-cm depth.

\begin{tabular}{|c|c|c|c|c|c|c|c|c|c|c|c|c|}
\hline & MHA-N & CaHA-N & $\begin{array}{l}\text { MHA-N } \\
\text { fraction }\end{array}$ & $\%$ clay & Soil pH & Exch. Ca & Exch. Mg & Exch. K & MHA-C/N & CaHA-C/N & MHA-E 4 & CaHA-E ${ }_{4}$ \\
\hline Total soil $\mathbf{N}$ & $0.83 * * *$ & 0.85 *** & - & - & - & - & - & - & - & - & $0.52 *$ & - \\
\hline MHA-N & & $0.59 *$ & $0.54 *$ & - & - & - & - & - & - & $-0.58 *$ & $0.62 *$ & - \\
\hline CaHA-N & & & - & - & - & - & - & - & - & - & - & $0.60 *$ \\
\hline MHA-N fraction & & & & - & $-\mathbf{0 . 7 2} * *$ & $-0.80 * * *$ & $-0.66^{* * *}$ & - & - & $-0.80 * * *$ & - & - \\
\hline$\%$ clay & & & & & - & - & $0.68 * *$ & - & $0.53 *$ & - & - & $0.59 *$ \\
\hline Soil pH & & & & & & $0.74 * *$ & - & - & - & $0.52 *$ & $-0.81^{* * * *}$ & - \\
\hline Exch. Ca & & & & & & & $0.76 * * *$ & - & - & $0.79 * * *$ & - & - \\
\hline Exch. Mg & & & & & & & & - & - & $0.61 *$ & - & - \\
\hline Exch. K & & & & & & & & & $0.58 *$ & - & - & - \\
\hline MHA-C/N & & & & & & & & & & - & - & - \\
\hline CaHA-C/N & & & & & & & & & & & - & - \\
\hline MHA-E 4 & & & & & & & & & & & & - \\
\hline
\end{tabular}

* Significant differences at the 0.05 probability level.

** Significant differences at the 0.01 probability level.

*** Significant differences at the 0.001 probability level.

$\dagger$ A dash means not significant.

$+\mathrm{E}_{4}$ optical density at $465 \mathrm{~nm}$. 

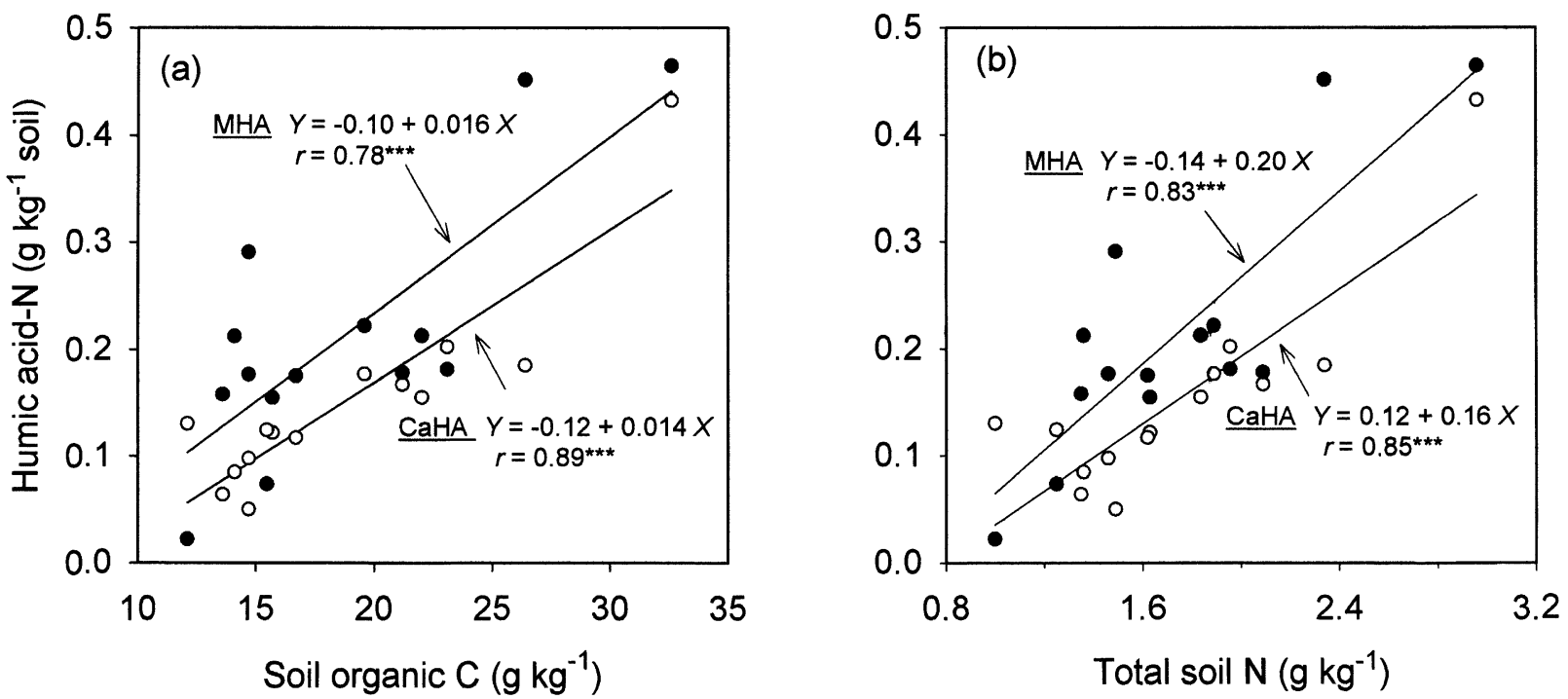

Fig. 2. The relationship between the amount of $\mathbf{N}$ extracted as the mobile humic acid fraction (MHA) or calcium humates (CaHA) versus (a) soil organic $C$ and (b) total soil $N$ for the 0 - to $15-\mathrm{cm}$ depth of 14 tropical lowland rice soils. The mean coefficient of variation across the 14 soils in the amount of extracted $\mathrm{N}$ contained in the MHA and CaHA fractions was $4 \%$ for the three field replicates of each soil. For soil organic $C$ and for total soil $N$ the mean coefficient of variation was $1 \%$ for three laboratory replicates of a composite soil.

\section{Correlation of Humic Fraction Properties with Soil Nitrogen Mineralization}

For each of the 12 soils, the temporal pattern of net $\mathrm{NH}_{4}-\mathrm{N}$ accumulation during the 84-d anaerobic incubation period was well described by the two-pool mineralization model of Eq. [1] (Table 5). Values for $N_{1}, k_{1}$, and $k_{2}$ varied greatly among soils, and the rate constant for the steady-state phase of $\mathrm{N}$ mineralization, $k_{2}$, was the most variable as indicated by the coefficients of variation for these parameters. Estimated values for the total size of rapidly mineralizable $\mathrm{N}\left(N_{1}\right)$ ranged from

Table 5. Estimated parameters and regression coefficients of a twopool first- and zero-order model $\left\{N_{t}=N_{1}\left[1-\exp \left(-k_{1} t\right)\right]+\right.$ $k_{2} t$ for the relationship between net $\mathrm{NH}_{4}-\mathrm{N}$ accumulation ( $Y=N_{\text {t }}$, in $\mathrm{mg} \mathrm{NH}_{4}-\mathrm{N} \mathrm{kg}^{-1}$ soil) and incubation time $(X=t$, in days) at $30^{\circ} \mathrm{C}$ under anaerobic incubation, and predicted rate of $\mathrm{NH}_{4}-\mathrm{N}$ accumulation for the 0 - to $15-\mathrm{cm}$ depth of 12 tropical lowland rice soils.

\begin{tabular}{|c|c|c|c|c|c|c|}
\hline \multirow[b]{2}{*}{ Soil } & \multicolumn{3}{|c|}{ Estimated parameters } & \multirow[b]{2}{*}{$R^{2}$} & \multicolumn{2}{|c|}{$\begin{array}{l}\text { Predicted rate of } \\
\text { NH-N accumulatio }\end{array}$} \\
\hline & $N_{1}^{\dagger}$ & $\boldsymbol{k}_{1} \dagger$ & $\boldsymbol{k}_{2} \dagger$ & & $7 \mathrm{~d}$ & $42 \mathrm{~d}$ \\
\hline & & & & & \multicolumn{2}{|c|}{$-\mathbf{m g ~ k g} \mathbf{k g}^{-1}$ soil $\mathbf{d}^{-1}$} \\
\hline Binhduc & 103 & 0.170 & 0.574 & $0.996 * *$ & 5.90 & 0.59 \\
\hline Cantho & 170 & 0.106 & 0.358 & $0.996 * *$ & 8.92 & 0.57 \\
\hline Huongso & 121 & 0.176 & 0.466 & $0.989 * *$ & 6.66 & 0.48 \\
\hline Longhiep & 67 & 0.056 & 0.200 & $0.997 * *$ & 2.72 & 0.55 \\
\hline Myyen & 57 & 0.089 & 0.157 & $0.994 * *$ & 2.88 & 0.28 \\
\hline Tambinh & 161 & 0.143 & 0.715 & $0.988 * *$ & 9.16 & 0.77 \\
\hline Thuybang & 107 & 0.162 & 0.560 & $0.985^{* *}$ & 6.12 & 0.58 \\
\hline Cuulong & 120 & 0.205 & 0.734 & $0.996 * *$ & 6.60 & 0.74 \\
\hline Guimba & 52 & 0.098 & 0.316 & $0.994 * *$ & 2.88 & 0.40 \\
\hline BIARC & 162 & 0.166 & 0.566 & $0.997 * *$ & 8.99 & 0.59 \\
\hline IRRI & 161 & 0.159 & 0.462 & $0.981 * *$ & 8.88 & 0.49 \\
\hline PhilRice & 132 & 0.118 & 0.270 & $0.996 * *$ & $\mathbf{7 . 0 7}$ & 0.38 \\
\hline Mean & 118 & 0.137 & 0.448 & & 6.40 & 0.54 \\
\hline Std dev. & 42 & 0.044 & 0.190 & & 2.45 & 0.14 \\
\hline CV, \% & 29 & 33 & 42 & & 38 & 26 \\
\hline
\end{tabular}

** Significant differences at the $\mathbf{0 . 0 1}$ probability level.

$\dagger N_{1}=$ total size of the rapidly mineralizable $\mathbf{N}$ pool $\left(\mathrm{mg} \mathrm{NH}_{4}-\mathbf{N ~ k g}^{-1}\right.$ soil), $k_{1}=$ rate constant for the rapid phase of $\mathrm{N}$ mineralization $(\mathrm{mg}$ $\mathrm{NH}_{4}-\mathrm{N} \mathrm{kg}^{-1}$ soil), and $k_{2}=$ rate constant for the steady-state phase of $\mathrm{N}$ mineralization ( $\mathrm{mg} \mathrm{NH}_{4}-\mathrm{N} \mathrm{kg}^{-1}$ soil).
$52 \mathrm{mg} \mathrm{NH} \mathrm{NH}_{4}-\mathrm{N} \mathrm{kg}^{-1}$ soil in the Guimba soil to $170 \mathrm{mg}$ $\mathrm{NH}_{4}-\mathrm{N} \mathrm{kg}^{-1}$ soil in the Cantho soil. The soils could be grouped into those with low $\left(N_{1}<75 \mathrm{mg} \mathrm{NH}_{4}-\mathrm{N} \mathrm{kg}^{-1}\right.$ soil, Fig. 3a), medium $\left(75<N_{1}<150 \mathrm{mg} \mathrm{NH}_{4}-\mathrm{N} \mathrm{kg}^{-1}\right.$ soil, Fig. 3b), and high $\left(N_{1}>150 \mathrm{mg} \mathrm{NH}_{4}-\mathrm{N} \mathrm{kg}^{-1}\right.$ soil, Fig. 3c) total amounts of rapidly mineralizable $\mathrm{N}$.

The rate of net $\mathrm{NH}_{4}-\mathrm{N}$ accumulation at 7 and $42 \mathrm{~d}$ was estimated by the first derivative of Eq. [1] for each soil (Table 5). These incubation times represent the midpoints of the two distinct phases of $\mathrm{N}$ mineralization identified by Cabrera (1993): the rapid phase from 0 to $14 \mathrm{~d}$ and the slower, nearly linear steady-state phase from 28 to $84 \mathrm{~d}$, separated by a transition period from 14 to $28 \mathrm{~d}$. The rate of net $\mathrm{NH}_{4}-\mathrm{N}$ mineralization at $7 \mathrm{~d}$ was, on average, 12-fold greater than that at $42 \mathrm{~d}$. Likewise, the coefficient of variation across soils in the rate of net $\mathrm{N}$ mineralization was about $50 \%$ larger at $7 \mathrm{~d}$ than at $42 \mathrm{~d}$.

The simple correlation between $N_{1}$ and soil organic $\mathrm{C}$ was not strong $(r=0.62)$ because the relationship between these parameters was curvilinear (Fig. 4). The relationship between $N_{1}$ and total soil $\mathrm{N}$ was similarly curvilinear $\left(R^{2}=0.58\right)$. Soil organic $\mathrm{C}$ and total soil $\mathrm{N}$ did not have curvilinear relationships with either the rate constant for the rapid phase of $\mathrm{N}$ mineralization, $k_{1}$, or the rate constant for the slow phase, $k_{2}$. Total soil $\mathrm{N}$ was weakly correlated with $k_{1}(r=0.52)$ and $k_{2}(r=$ $0.60)$. Stepwise regression using either soil organic $C$ and its square or total soil $\mathrm{N}$ and its square, together with other whole soil properties (Model 1), did not improve the prediction of variation in $N_{1}$ (Table 6), $k_{1}$ (Table 7), or $k_{2}$ (Table 8 ) beyond the simple regressions. Soil organic $\mathrm{C}$ parameters were not run in the same stepwise regressions as total soil $\mathrm{N}$ parameters because of their colinearity; each stepwise regression included the set of parameters that provided better fit.

Prediction of the three kinetic parameters was improved significantly through stepwise regressions that 

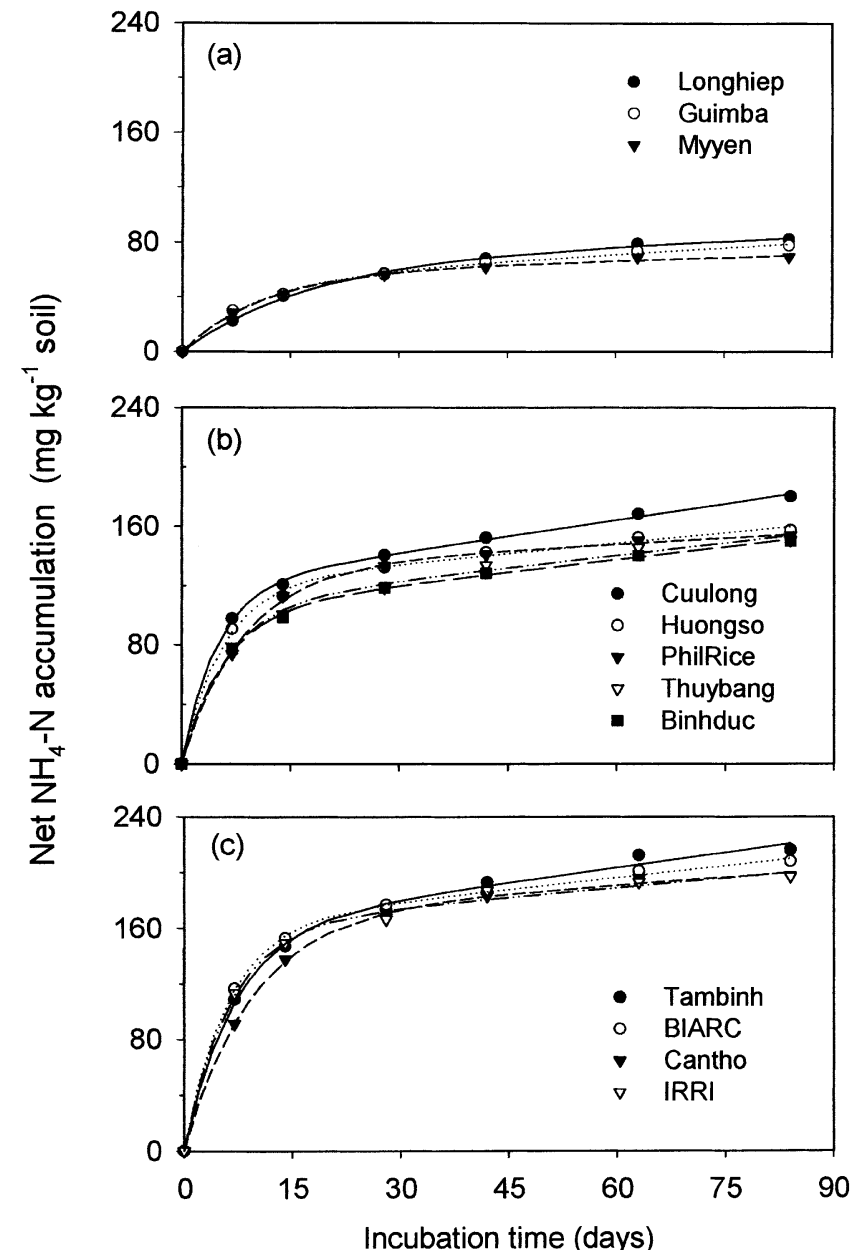

Fig. 3. Net cumulative $\mathrm{NH}_{4}-\mathrm{N}$ accumulation during anaerobic incubation of (a) soils having $N_{1}<75 \mathrm{mg} \mathrm{NH}_{4}-\mathrm{N} \mathrm{kg}^{-1}$ soil, (b) soil having $75<N_{1}<150 \mathrm{mg} \mathrm{NH}_{4}-\mathrm{N} \mathrm{kg}^{-1}$ soil, and (c) soil having $N_{1}>$ $150 \mathrm{mg} \mathrm{NH}-\mathrm{N} \mathrm{kg}^{-1}$ soil, where $N_{1}$ is the total size of the rapidly mineralizable $\mathbf{N}$ pool. Curves shown are regression lines based on the two-pool first- and zero-order model using parameters given in Table 5. Soil was sampled from the 0- to 15-cm depth.

included variables related to the quantity or quality of the HA fractions. For example, 95 to $97 \%$ of the variation in $N_{1}$ was explained by regressions that included soil organic $\mathrm{C}$ and its squared term plus smaller contributions from the MHA-N fraction and the $\mathrm{E}_{4}$ values of the MHA and CaHA (Table 6). For $k_{1}$ (Table 7), CaHA quantity $(\mathrm{CaHA}-\mathrm{N})$ and quality $\left(\mathrm{CaHA}-\mathrm{E}_{4}\right)$ variables (Model 3) provided better prediction than did the six soil variables (Model 1) or MHA variables (data not shown), but the best overall prediction $\left(R^{2}=0.64, P=\right.$ 0.006 ) was provided by a mix of soil and MHA variables (Models 2 and 4): total soil $\mathrm{N}$, exchangeable $\mathrm{K}$, and MHA-C/N. For $k_{2}$, the rate constant for the steadystate phase of $\mathrm{N}$ mineralization (Table 8), CaHA-N and $\mathrm{CaHA}-\mathrm{E}_{4}$ again provided better prediction than did soil variables alone or MHA variables alone (data not shown). And as with $k_{1}$, the best overall prediction of $k_{2}\left(R^{2}=0.75, P=0.008\right)$ was provided by total soil $\mathrm{N}$, exchangeable $\mathrm{K}$, and MHA-C/N. Both rate constants were positively associated with total soil $\mathrm{N}$ and exchangeable $\mathrm{K}$ and negatively associated with MHA-C/N.

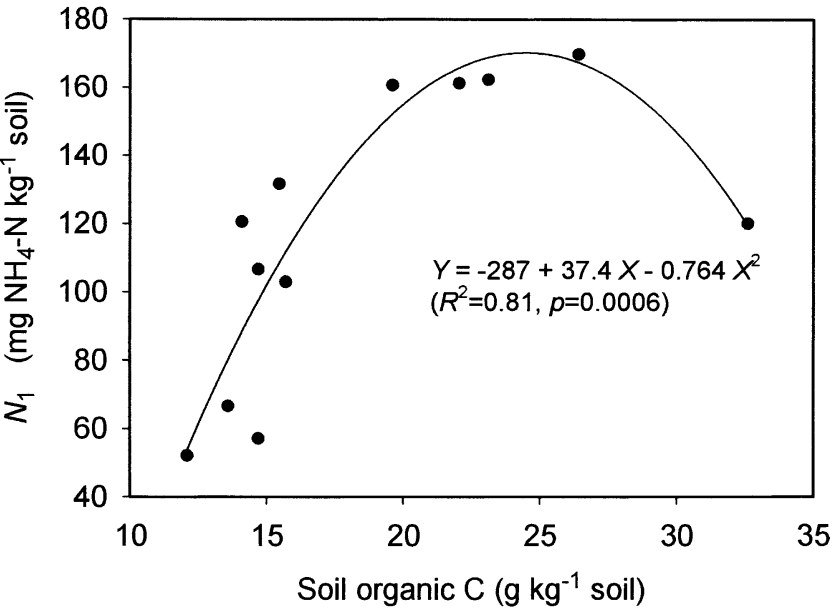

Fig. 4. The relationship between $N_{1}$ (total size of the rapidly mineralizable $N$ pool) and soil organic $C$ for the $0-$ to $15-\mathrm{cm}$ depth of 12 tropical lowland rice soils. Standard errors for the regression equation are 75 (intercept), 7.4 ( $x$ term), and 0.169 $\left(x^{2}\right.$ term). Each data point represents the mean of three replicates.

\section{DISCUSSION}

Irrigated soils in lowland, tropical environments that produce two and sometimes three rice crops per year remain under anoxic conditions for much of the year. Rice soils quickly become anoxic when crop residues are incorporated during the puddling operation in preparation for planting, and they remain anoxic throughout most of the growing season because floodwaters are maintained at a 5- to $10-\mathrm{cm}$ depth to reduce weed pressure (De Datta, 1981). These conditions differ markedly from the aerated soil conditions that typify the production of all other major food crops. The anoxic conditions in lowland rice soils alter the amount and chemical composition of labile SOM compared with the labile SOM that forms in aerated soils (Olk et al., 1996). At issue is (i) whether such effects vary among rice soils in manners that influence the temporal pattern of soil $\mathrm{N}$ mineralization, and (ii) whether specific properties of the chemically extracted HA fractions can be associated with the effects on $\mathrm{N}$ mineralization. Such information will lead to better understanding of the role that labile SOM plays in $\mathrm{N}$ mineralization of lowland rice soils.

\section{Formation and Quality of Labile Organic Matter Fractions}

Results from the current study are consistent with results from previous studies that identified the MHA as a younger SOM fraction than the CaHA (Olk et al., 1995; Mahieu et al., 2002). The MHA had lower C and higher $\mathrm{N}$ concentrations, smaller $\mathrm{C} / \mathrm{N}$ ratios and $\mathrm{E}_{4}$ values, and lighter colors than the CaHA, indicating a less humified state (Schnitzer and Lévesque, 1979; Mahieu et al., 2002). These properties differed consistently in each of the 14 soils of this study, suggesting that the MHA and CaHA represent distinct organic $\mathrm{N}$ fractions across a wide range of lowland rice soils. Previous studies of lowland rice soils have shown the CaHA is intermediate between the MHA and whole SOM in its (i) changes in $\mathrm{N}$ and $\mathrm{C}$ content in response to recent rice 
Table 6. Coefficients that contribute to the explanation of the $N_{1}$ parameter (total size of the rapidly mineralizable $\mathbf{N}$ pool) based on stepwise regression of $N_{1}$ on independent variables that include properties of 12 tropical lowland rice soils and their humic acid fractions. Value in parentheses for each coefficient is its partial regression $R^{2}$. X indicates the variable did not meet the $P<0.15$ level for entry into the model. Soil was sampled from the 0 - to $15-\mathrm{cm}$ depth. $\dagger$

\begin{tabular}{|c|c|c|c|c|}
\hline Variable $\dagger$ & $\begin{array}{l}\text { Model } 1 \\
\text { Soil }\end{array}$ & $\begin{array}{c}\text { Model 2 } \\
\text { Soil }+ \text { MHA }\end{array}$ & $\begin{array}{c}\text { Model 3 } \\
\text { Soil + CaHA }\end{array}$ & $\begin{array}{c}\text { Model } 4 \\
\text { All }\end{array}$ \\
\hline Intercept & $-286 * *$ & $-124 *$ & $-95^{\mathrm{ns}} \%$ & $-100^{\mathrm{ns}}$ \\
\hline Soil organic $\mathrm{C}, \mathrm{g} \mathrm{kg}^{-1}$ soil & $37.4 * * *\left(\boldsymbol{R}^{2}=\mathbf{0 . 3 8}\right)$ & $21.4 * *\left(R^{2}=0.38\right)$ & $28.2 * * *\left(\boldsymbol{R}^{2}=\mathbf{0 . 3 8}\right)$ & $25.2 * * *\left(R^{2}=0.38\right)$ \\
\hline$(\text { Soil organic C) })^{2},\left[\mathrm{~g} \mathrm{~kg}^{-1} \text { soil }\right]^{2}$ & $-0.764 * *\left(R^{2}=0.43\right)$ & $-0.353 *\left(R^{2}=0.43\right)$ & $-0.519 * *\left(R^{2}=0.43\right)$ & $-0.445^{* *} *\left(R^{2}=0.43\right)$ \\
\hline MHA-C, $\mathrm{g} \mathrm{kg}^{-1}$ soil & & $\mathbf{x}$ & & $\mathbf{x}$ \\
\hline MHA-N, g kg $\mathbf{k g}^{-1}$ soil & & $\mathbf{x}$ & & $\mathbf{x}$ \\
\hline MHA-C/N & & $\mathbf{x}$ & & $\mathbf{x}$ \\
\hline MHA-E ${ }_{4}$, OD units (g MHA-C L L $\left.{ }^{-1}\right)^{-1}$ & & $-16.1 * * *\left(\boldsymbol{R}^{2}=0.09\right)$ & & $-6.84 *\left(R^{2}=0.05\right)$ \\
\hline MHA-N fraction & & $0.870 * *\left(R^{2}=0.07\right)$ & $-0.533^{\text {ns }}\left(R^{2}=0.04\right)$ & $\mathbf{x}$ \\
\hline CaHA-C, $\mathrm{g} \mathrm{kg}^{-1}$ soil & & & $\mathbf{x}$ & $\mathbf{x}$ \\
\hline CaHA-N, g kg ${ }^{-1}$ soil & & & $\mathbf{x}$ & $\mathbf{x}$ \\
\hline CaHA-C/N & & & $\mathbf{x}$ & $\mathbf{x}$ \\
\hline $\mathrm{CaHA}_{4} \mathrm{E}_{4},\left(\mathrm{OD}\right.$ units $\left(\mathrm{g} \text { MHA-C } \mathrm{L}^{-1}\right)^{-1}$ & & & $-7.61 * *\left(R^{2}=0.10\right)$ & $-4.65^{*}\left(R^{2}=0.10\right)$ \\
\hline $\mathbf{R}^{2}+4 x^{2}$ & $0.81 * * *$ & $0.97 * * *$ & $0.95 * * *$ & $0.96^{* * * *}$ \\
\hline
\end{tabular}

* Significant differences at the 0.05 probability level.

** Significant differences at the 0.01 probability level.

**** Significant differences at the 0.001 probability level.

†Soil variables that did not meet the $\boldsymbol{P}<0.15$ level for entry into preliminary stepwise analyses were soil $\mathrm{C} / \mathrm{N}$ ratio, soil pH, $1 M$ NH - extractable $\mathrm{Ca}$, and $1 M$ NH $_{4}$-extractable $\mathrm{K}$. MHA = mobile humic acids; CaHA = calcium humates; $\mathrm{K}_{\mathrm{ex}}=1 \mathrm{M} \mathrm{NH}_{4}-\mathrm{extractable}_{\mathrm{K}}$; $\mathbf{E}_{4}=$ optical density at wavelength $465 \mathrm{~nm}$.

$\uparrow$ Not significant.

crop management (Olk et al., 1998), (ii) contents of lignin residues and other aromatic compounds (Olk et al., 2002), and (iii) seasonal fluxes of labeled urea $\mathrm{N}$ (Olk and Cassman, 2002).

Despite the consistency of qualitative differences between the MHA and CaHA found in the 14 soils, the amounts and properties of each HA fraction varied considerably among the soils. For example, their $\mathrm{C}$ and $\mathrm{N}$ contents were more variable than were soil organic $\mathrm{C}$ or total soil N, suggesting the MHA and $\mathrm{CaHA}$ are more sensitive to environmental and management factors than is bulk SOM. Results also indicated large variations in their degree of humification. Humification of MHA increased with shortened time of soil drying during the fallow period between crop seasons, which is the only extended period of aerated conditions in double- and triple-cropped rice soils. The most aerated fal- low conditions occurred in the Guimba and PhilRice soils, which completely dry in the surface layer and crack extensively in most fallow periods between the wet and dry seasons (Olk et al., 1998). The MHA from these soils also had the lowest $\mathrm{E}_{4}$ values. In previous studies, the PhilRice MHA was shown to be less humified than the MHA fractions of wetter rice soils based on its organic $\mathrm{N}$ forms (Mahieu et al., 2000a), organic $\mathrm{P}$ forms, (Mahieu et al., 2000b), N, H, and O elemental concentrations, and organic free radical concentration (Olk et al., 1999). These chemical characteristics were also well correlated with $\mathrm{E}_{4}$ (Mahieu et al., 2002). Younger, unprotected SOM in such soils may be extensively decomposed during aerated fallows, so that the MHA would be of small mass and consist of only the youngest, most recently formed humic materials. The CaHA fraction

Table 7. Coefficients that contribute to the explanation of the $k_{1}$ parameter (rate constant for the rapidly mineralizable $\mathbf{N}$ pool) based on stepwise regression of $k_{1}$ on independent variables that include properties of 12 tropical lowland rice soils and their humic acid fractions. Value in parentheses for each coefficient is its partial regression $R^{2}$. $X$ indicates the variable did not meet the $P<0.15$ level for entry into the model. Soil was sampled from the 0- to $15-\mathrm{cm}$ depth.

\begin{tabular}{|c|c|c|c|c|}
\hline Variable $\dagger$ & $\begin{array}{l}\text { Model } 1 \\
\text { Soil }\end{array}$ & $\begin{array}{c}\text { Model 2 } \\
\text { Soil }+ \text { MHA }\end{array}$ & $\begin{array}{c}\text { Model 3 } \\
\text { Soil + CaHA }\end{array}$ & $\begin{array}{c}\text { Model } 4 \\
\text { All }\end{array}$ \\
\hline Intercept & $0.0654^{\mathrm{ns}} \leftarrow$ & $0.484 *$ & $0.186 * * *$ & $0.484^{*}$ \\
\hline Total soil $\mathbf{N}, \mathrm{g} \mathrm{kg}^{-1}$ soil & $0.0419^{\text {ns }}\left(R^{2}=0.27\right)$ & $0.0516 *\left(R^{2}=0.27\right)$ & $\mathbf{x}$ & $0.0516^{*}\left(R^{2}=0.27\right)$ \\
\hline Soil $\mathrm{K}_{\mathrm{ex}}, \mathrm{cmol} \mathrm{kg}^{-1}$ soil & $\mathbf{x}$ & $0.0548^{\mathrm{ns}}\left(R^{2}=0.16\right)$ & $\mathbf{x}$ & $0.0548^{\text {ns }}\left(R^{2}=0.16\right)$ \\
\hline MHA-C, $\mathrm{g} \mathrm{kg}^{-1}$ soil & & $\mathbf{x}$ & & $\mathbf{x}$ \\
\hline MHA-N, $\mathbf{g ~ k g}^{-1}$ soil & & $\mathbf{x}$ & & $\mathbf{x}$ \\
\hline MHA-C/N & & $-0.0444 *\left(R^{2}=0.21\right)$ & & $-0.0444 *\left(R^{2}=0.21\right)$ \\
\hline $\begin{array}{l}\text { MHA-E }{ }_{4}, \text { OD units } \\
\quad\left(\mathrm{g} \text { MHA-C L } \mathbf{L}^{-1}\right)^{-1}\end{array}$ & & 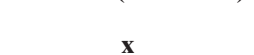 & & 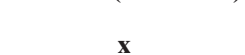 \\
\hline MHA-N fraction & & $\mathbf{x}$ & $\mathbf{x}$ & $\mathbf{x}$ \\
\hline CaHA-C, $\mathrm{g} \mathrm{kg}^{-1}$ soil & & & $\mathbf{x}$ & $\mathbf{x}$ \\
\hline CaHA-N, $\mathrm{g} \mathrm{kg}^{-1}$ soil & & & $0.408 * *\left(R^{2}=0.26\right)$ & $\mathbf{x}$ \\
\hline CaHA-C/N & & & $\mathbf{x}$ & $\mathbf{x}$ \\
\hline $\begin{array}{r}\text { CaHA-E }{ }_{4}, \text { OD units } \\
\quad\left(\mathrm{g} \text { MHA-C L L } \mathbf{L}^{-1}\right)^{-1}\end{array}$ & & & $-0.0100 *\left(R^{2}=0.30\right)$ & $\mathbf{x}$ \\
\hline$R^{2}$ & $0.27^{\mathrm{ns}}$ & $0.64 *$ & $0.56^{*}$ & $0.64 *$ \\
\hline
\end{tabular}

* Significant differences at the 0.05 probability level.

** Significant differences at the 0.01 probability level.

**** Significant differences at the 0.001 probability level.

$\dagger$ Soil variables that did not meet the $P<0.15$ level for entry into preliminary stepwise analyses were (Total soil $\mathbf{P})^{2}$, soil $\mathrm{C} / \mathrm{N}$ ratio, soil pH, and $1 \mathrm{M}$

$\mathrm{NH}_{4}$-extractable Ca; MHA = mobile humic acids; CaHA = calcium humates; $\mathrm{K}_{\mathrm{ex}}=1 M \mathrm{NH}_{4}-$ extractable $\mathrm{K}$; $\mathbf{E}_{4}=$ optical density at wavelength 465 nm.

+ Not significant. 
Table 8. Coefficients that contribute to the explanation of the $k_{2}$ parameter (rate constant for the steady-state phase of $\mathbf{N}$ mineralization) based on stepwise regression of $k_{2}$ on independent variables that include properties of 12 tropical lowland rice soils and their humic acid fractions. Value in parentheses for each coefficient is its partial regression $\mathbf{R}$-square. $\mathbf{X}$ indicates the variable did not meet the $P<0.15$ level for entry into the model. Soil was sampled from the 0 - to $15-\mathrm{cm}$ depth.

\begin{tabular}{|c|c|c|c|c|}
\hline Variable $\dagger$ & $\begin{array}{c}\text { Model } 1 \\
\text { Soil }\end{array}$ & $\begin{array}{c}\text { Model 2 } \\
\text { Soil + MHA }\end{array}$ & $\begin{array}{c}\text { Model 3 } \\
\text { Soil + CaHA }\end{array}$ & $\begin{array}{c}\text { Model } 4 \\
\text { All }\end{array}$ \\
\hline Intercept & $0.0818^{\mathrm{n} s}+$ & $1.98 * *$ & $0.679 * * *$ & $1.98 * *$ \\
\hline Total soil $\mathbf{N}, \mathbf{g ~ k g}^{-1}$ soil & $0.214 *\left(R^{2}=0.36\right)$ & $0.268 * *\left(R^{2}=0.36\right)$ & $\mathbf{x}$ & $0.268^{* *}\left(R^{2}=0.36\right)$ \\
\hline Soil $K_{\mathrm{ex}}, \mathrm{cmol} \mathrm{kg}^{-1}$ soil & $\mathbf{x}$ & $0.176^{\mathrm{ns}}\left(R^{2}=0.09\right)$ & $\mathbf{x}$ & $0.176^{\text {ns }}\left(R^{2}=0.09\right)$ \\
\hline MHA-C, $\mathrm{g} \mathrm{kg}^{-1}$ soil & & $\mathbf{x}$ & & $\mathbf{x}$ \\
\hline MHA-N, $\mathbf{g ~ k g}^{-1}$ soil & & $\mathbf{x}$ & & $\mathbf{x}$ \\
\hline MHA-C/N & & $-0.200 * *\left(R^{2}=0.30\right)$ & & $-0.200 * *\left(R^{2}=\mathbf{0 . 3 0}\right)$ \\
\hline $\begin{array}{l}\text { MHA-E } \\
\left(\text { g MHA-C L L L }{ }^{-1}\right)^{-1}\end{array}$ & & 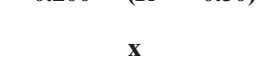 & & 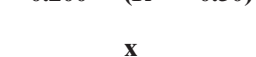 \\
\hline MHA-N fraction & & $\mathbf{x}$ & $\mathbf{x}$ & $\mathbf{x}$ \\
\hline CaHA-C, $\mathrm{g} \mathrm{kg}^{-1}$ soil & & & $\mathbf{x}$ & $\mathbf{x}$ \\
\hline CaHA-N, $\mathrm{g} \mathrm{kg}^{-1}$ soil & & & $1.96 * * *\left(R^{2}=0.32\right)$ & $\mathbf{x}$ \\
\hline CaHA-C/N & & & $\mathbf{x}$ & $\mathbf{x}$ \\
\hline CaHA-E ${ }_{4}$, OD units & & & & \\
\hline$R^{\left({ }^{2}\right.}\left(\mathrm{MHA}-\mathrm{C} \mathrm{L} \mathrm{L}^{-1}\right)^{-1}$ & $0.36 *$ & $0.75 * *$ & $\begin{array}{c}-0.0476 *\left(R^{2}=0.35\right) \\
0.67 * *\end{array}$ & $\begin{array}{c}\mathbf{x} \\
\mathbf{0 . 7 5} * *\end{array}$ \\
\hline
\end{tabular}

* Significant differences at the 0.05 probability level.

** Significant differences at the 0.01 probability level.

*** Significant differences at the 0.001 probability level.

$\dagger$ Soil variables that did not meet the $P<0.15$ level for entry into preliminary stepwise analyses were (Total soil $\mathbf{N})^{2}$, soil $\mathrm{C} / \mathrm{N}$ ratio, soil pH, and $1 M$

$\mathrm{NH}_{4}$-extractable Ca. MHA = mobile humic acids; CaHA = calcium humates; $\mathrm{K}_{\mathrm{ex}}=1 \mathrm{M} \mathrm{NH}_{4}$-extractable $\mathrm{K}$; $\mathrm{E}_{4}=$ optical density at wavelength 465 nm. † Not significant.

would be better protected against this microbial degradation through its stabilization by polyvalent cations.

In contrast, the Cantho and Cuulong soils are covered by deep floodwaters of the Mekong River during most of the fallow period, and their MHA have large $\mathrm{E}_{4}$ values and relatively high $\mathrm{C} / \mathrm{N}$ ratios. Such flooded conditions would slow SOM mineralization, especially for labile materials like the MHA. Newly formed SOM would survive long enough to undergo humification, resulting in relatively large yet humified HA fractions. Hence, $\mathrm{E}_{4}$ was positively correlated with the amounts of $\mathrm{N}$ and $\mathrm{C}$ contained in these two HA fractions. While the positive correlations of HA quantities with soil organic $\mathrm{C}$ and total soil $\mathrm{N}$ indicate that quantities of all SOM pools are heavily influenced by the net balance between the input rates of incorporated crop residues and the decomposition rates of these residues and SOM, the proportion of time the soil remains flooded and under anoxic conditions also appears to modify this balance by affecting the quantity and quality of the HA fractions.

Although the quantities of soil organic $\mathrm{C}$ and total soil $\mathrm{N}$ were not correlated with soil $\mathrm{pH}$ or the amounts of exchangeable cations, three of the four HA quality parameters had at least one significant correlation with soil $\mathrm{pH}$ or an exchangeable cation. In particular, exchangeable $\mathrm{Ca}$ appeared to promote formation or stabilization of the CaHA fraction at the expense of the MHA fraction, because the divalent Ca had strong negative correlations with the MHA-N fraction (the ratio of MHA-N to the sum of MHA-N and CaHA-N) and with the MHA-C and -N in stepwise regressions. Conversely, stepwise analysis associated monovalent $\mathrm{K}$ positively with the MHA-N fraction and negatively with CaHA-C. Calcium contributed substantially to stepwise prediction of $\mathrm{CaHA}-\mathrm{C} / \mathrm{N}$, while $\mathrm{K}$ contributed substantially to stepwise prediction of MHA-C/N. We speculate that the relative abundances of polyvalent versus monovalent cations may govern whether newly formed SOM is stabi- lized through strong bonding with divalent cations, thereby becoming extractable as CaHA, or is bound more loosely to monovalent cations, thereby becoming extractable as MHA. Given the clear differences in chemical properties between the MHA and CaHA and in their contributions to soil N cycling (Olk and Cassman, 2002), binding of SOM to exchangeable soil cations would seem an important control of its subsequent cycling, consistent with conclusions from previous studies (Baldock and Skjemstad, 2000; Bruckert et al., 1994; Kononova, 1961).

\section{Controls on Soil Nitrogen Mineralization and Inferences for Crop Nitrogen Supply}

The two-pool first- and zero-order model provided an excellent fit to the temporal pattern of net $\mathrm{N}$ mineralization observed during the laboratory incubations of the 12 lowland rice soils. Prediction of the two rate constants in the model was poor when based on regressions using solely whole soil properties. Inclusion of parameters that provide information about the quantity and quality of the MHA and CaHA fractions increased the predictive power of the regressions for all three mineralization parameters. Stepwise regressions that included both total soil $\mathrm{N}$ and the $\mathrm{C} / \mathrm{N}$ ratio of the MHA as independent variables explained the greatest amount of variation in the two rate constants. The $\mathrm{C} / \mathrm{N}$ ratio of the MHA fraction had a negative coefficient in these best-fit regressions, which is analogous to the faster rate of $\mathrm{N}$ mineralization from crop residues and other organic materials that have a smaller $\mathrm{C} / \mathrm{N}$ ratio (Stevenson and Cole, 1999). Exchangeable $\mathrm{K}$ had a positive coefficient in the best-fit regressions for both $k_{1}$ and $k_{2}$. The mechanism for these positive relationships cannot be determined from this study, but they are consistent with our speculation that the binding of SOM, and its susceptibility to mineralization, is influenced by exchangeable cations; SOM is likely bound more tightly to soil surfaces 
with a high exchangeable Ca content than those with a high exchangeable K content.

The degree of humification in the CaHA fraction, as estimated by its $\mathrm{E}_{4}$ absorbance values, was also found to be a relatively sensitive independent variable for the two rate constants: greater humification (i.e., higher $\mathrm{E}_{4}$ values) was associated with slower rates of net $\mathrm{N}$ mineralization in stepwise Model 3 that included soil and CaHA variables (Tables 7 and 8). In addition, the $\mathrm{E}_{4}$ values of both HA fractions, in combination with soil organic $\mathrm{C}$ and its square, explained nearly all of the variation in the total size of the rapidly mineralizable $\mathrm{N}$ pool, $N_{1}$, and again, the $\mathrm{E}_{4}$ term for both fractions had negative coefficients (Table 6). The significant relationship between $N_{1}$ and soil organic C (Fig. 4) may result from the accumulation of humified, poor quality SOM under the anoxic conditions of lowland rice cropping. This material likely became available at the beginning of the incubation, during the flush of microbial activity that occurs when dried soils are rewetted (Duxbury and Nkambule, 1994).

Of the three kinetic parameters that define the pattern and rate of soil $\mathrm{N}$ mineralization in the two-pool model, the most important may be $k_{2}$, which best represents the steady-state soil $\mathrm{N}$ supply during the period of greatest crop $\mathrm{N}$ demand, from panicle initiation to maturity (Cassman et al., 1998). While a greater amount of soil $\mathrm{N}$ is mineralized during the rapid phase, which in field conditions may occur for about $28 \mathrm{~d}$ after the soil flooding and puddling operations, there is little crop $\mathrm{N}$ uptake during this period of planting and early vegetative growth. In addition, as the $\mathrm{NH}_{4}^{+}$from rapid-phase mineralization accumulates, it is quickly lost to volatilization and denitrification along with $\mathrm{NH}_{4}^{+}$from applied $\mathrm{N}$ fertilizer. Indeed, available inorganic $\mathrm{N}$ remains at very low levels throughout the last half of crop growth because $\mathrm{N}$ fertilizer is generally applied at planting and before panicle initiation (Peng and Cassman, 1998; Witt et al., 1998), which suggests that the majority of crop $\mathrm{N}$ uptake after panicle initiation is derived from soil $\mathrm{N}$ mineralization. Despite the importance of the steadystate phase of $\mathrm{N}$ mineralization to $\mathrm{N}$ uptake by the rice crop, prediction of soil $\mathrm{N}$ supply in the late season has not been possible. The improved prediction of variation in the $k_{2}$ parameter by stepwise regressions that included both soil and MHA parameters $\left(R^{2}=0.75\right)$ as compared with soil parameters alone $\left(R^{2}=0.36\right)$ indicates that a better understanding of the role of this labile HA fraction in $\mathrm{N}$ mineralization provides a promising avenue for improving the prediction of soil $\mathrm{N}$ supply during the steady-state phase.

\section{CONCLUSIONS}

Net $\mathrm{N}$ mineralization during laboratory incubation of tropical lowland rice soils was described by three kinetic parameters of a two-pool model. In stepwise regression, two of the three parameters were poorly predicted by soil organic C, total soil $\mathrm{N}$, and other properties of whole soil. Prediction of the mineralization parameters was improved with the inclusion of properties of two distinct
HA fractions, the MHA and CaHA, which together contained 15 to $30 \%$ of total soil N. In particular, the degree of humification in these fractions was negatively associated with net $\mathrm{N}$ mineralization, which suggests that more recalcitrant forms of these humic acids are formed under anoxic conditions, resulting in slower rates of $\mathrm{N}$ mineralization per unit of accumulated organic $\mathrm{N}$ in these labile HA pools. The balance of divalent versus monovalent cations may affect whether newly formed SOM is stabilized against mineralization through strong cationic bonding or instead remains loosely bound and more prone to mineralization. Selected humic properties were not affected by air-drying of the soil before extraction of the humic fractions, which suggests that study of the HA fractions extracted from air-dried soil can provide useful information about their contributions to soil $\mathrm{N}$ mineralization. Results indicate the relevance of chemically extracted HA fractions to investigations into the biophysical controls on soil $\mathrm{N}$ mineralization and $\mathrm{N}$ supply to lowland rice in intensive, irrigated systems of tropical Asia.

\section{ACKNOWLEDGMENTS}

This work was conducted during the authors' tenure at the International Rice Research Institute. They thank IRRI for providing the senior author with a graduate research assistantship and D.W. Meek for assistance with statistical analyses. Completion of this work was partially supported by funds from the USDA-ARS and the Hatch Act provided through the University of Nebraska Agricultural Research Division, Lincoln, NE.

\section{REFERENCES}

Anderson, D.W. 1979. Processes of humus formation and transformation in soils of the Canadian Great Plains. J. Soil Sci. 30:77-84.

Baldock, J.A., and J.O. Skjemstad. 2000. Role of the soil matrix and minerals in protecting natural organic materials against biological attack. Org. Geochem. 31:697-710.

Bird, J.A., C. van Kessel, and W.R. Horwath. 2003. Stabilization of ${ }^{13} \mathrm{C}$-carbon and immobilization of ${ }^{15} \mathrm{~N}$-nitrogen from rice straw in humic fractions. Soil Sci. Soc. Am. J. 67:806-816.

Boone, R.D. 1994. Light-fraction soil organic matter: Origin and contribution to net nitrogen mineralization. Soil Biol. Biochem. 26: 1459-1468.

Bruckert, S., M. Gaiffe, J.L. Blondé, and J.M. Portal. 1994. Fractionnement de la matière organique et analyse des composés humiques des sols calcimagnésiques humifères du Jura (France). Geoderma 61:269-280.

Buresh, R.J., and S.K. De Datta. 1990. Denitrification losses from puddled rice soils in the tropics. Biol. Fertil. Soils 9:1-13.

Cabrera, M.L. 1993. Modeling the flush of nitrogen mineralization caused by drying and rewetting soils. Soil Sci. Soc. Am. J. 57:63-66.

Cadisch, G., H. Imhof, S. Urquiaga, R.M. Boddey, and K.E. Giller. 1996. Carbon turnover $\left(\delta^{13} \mathrm{C}\right)$ and nitrogen mineralization potential of particulate light soil organic matter after rainforest clearing. Soil Biol. Biochem. 28:1555-1567.

Campbell, C.A., E.A. Paul, D.A. Rennie, and K.J. McCallum. 1967. Applicability of the carbon-dating method of analysis to soil humus studies. Soil Sci. 104:217-224.

Cassman, K.G., S.K. De Datta, D.C. Olk, J.M. Alcantara, M.I. Samson, J.P. Descalsota, and M.A. Dizon. 1995. Yield decline and the nitrogen economy of long-term experiments on continuous irrigated rice systems in the tropics. p. 181-222. In R. Lal and B.A. Stewart (ed.) Soil management: Experimental basis for sustainability and environmental quality. Lewis/CRC, Boca Raton, FL.

Cassman, K.G., A. Dobermann, P.C. Sta. Cruz, G.C. Gines, M.I. Samson, J.P. Descalsota, J.M. Alcantara, M.A. Dizon, and D.C. 
Olk. 1996a. Soil organic matter and the indigenous nitrogen supply of intensive irrigated rice systems in the tropics. Plant Soil 182: 267-278.

Cassman, K.G., G.C. Gines, M.A. Dizon, M.I. Samson, and J.M. Alcantara. 1996b. Nitrogen-use efficiency in tropical lowland rice systems: Contributions from indigenous and applied nitrogen. Field Crops Res. 47:1-12.

Cassman, K.G., S. Peng, D.C. Olk, J.K. Ladha, W. Reichardt, A. Dobermann, and U. Singh. 1998. Opportunities for increased nitrogen-use efficiency from improved resource management in irrigated rice systems. Field Crops Res. 56:7-39.

Chen, Y., N. Senesi, and M. Schnitzer. 1977. Information provided on humic substances by $E_{4} / E_{6}$ ratios. Soil Sci. Soc. Am. J. 41:352-358.

Christensen, B.T. 1992. Physical fractionation of soil and organic matter in primary particle size and density separates. Adv. Agron. 20:1-90.

De Datta, S.K. 1981. Principles and practices of rice production. Wiley, New York.

Devêvre, O.C., and W.R. Horwath. 2001. Stabilization of fertilizer nitrogen-15 into humic substances in aerobic vs. waterlogged soil following straw incorporation. Soil Sci. Soc. Am. J. 65:499-510.

Duxbury, J.M., and S.V. Nkambule. 1994. Assessment and significance of biologically active soil organic nitrogen. p. 125-146. In J.W. Doran et al. (ed.) Defining soil quality for a sustainable environment. SSSA Spec. Pub. 35. SSSA, Madison, WI.

Feller, C., and M.H. Beare. 1997. Physical control of soil organic matter dynamics in the tropics. Geoderma 79:69-116.

Freund, R.J., and R.C. Littell. 1991. Multicollinearity: Detection and remedial measures. p. 93-125. In SAS system for regression. 2nd ed. SAS Institute, Cary, NC.

Gee, G.W., and J.W. Bauder. 1986. Particle-size analysis. p. 383-411. In A. Klute (ed.) Methods of soil analysis. Part 1.2nd ed. Agron. Monogr. 9. ASA and SSSA, Madison, WI.

Great Britain Ministry of Agriculture, Fisheries, and Food. 1981. Cation exchange capacity and exchangeable cations in the soil. p. 197-203. In The analysis of agricultural materials: A manual of the analytical methods used by the Agricultural Development and Advisory Service. 2nd ed. Her Majesty's Stationery Office, London.

Jenkinson, D.S., and J.H. Rayner. 1977. The turnover of soil organic matter in some of the Rothamsted classical experiments. Soil Sci. 123:298-305.

Kawaguchi, K., and K. Kyuma. 1977. Paddy soils of tropical Asia: Their nature and fertility. Univ. of Hawaii Press, Honolulu.

Kempers, A.J., and A. Zweers. 1986. Ammonium determination in soil extracts by the salicylate method. Commun. Soil Sci. Plant Anal. 17:715-723

Kononova, M.M. 1961. The natural factors of humus formation. p. 203-230. In Soil organic matter: Its nature, its role in soil formation and in soil fertility. Pergamon Press, New York.

Kumada, K. 1987. Chemistry of soil organic matter. Japan Scientific Society, Tokyo.

Ladd, J.N., J.W. Parsons, and M. Amato. 1977. Studies of nitrogen immobilization and mineralization in calcareous soils - I. Distribution of immobilized nitrogen amongst soil fractions of different particle size and density. Soil Biol. Biochem. 9:309-318.

MacCarthy, P. 2001. The principles of humic substances: An introduction to the First Principle. p. 19-30. In E.A. Ghabbour and G. Davies (ed.) Humic substances: Structures, models, and functions. Royal Society of Chemistry, Cambridge, UK.

Mahieu, N., D.C. Olk, and E.W. Randall. 2000a. Accumulation of heterocyclic nitrogen in humified organic matter: ${ }^{15} \mathrm{~N}$ NMR study of lowland rice soils. Eur. J. Soil Sci. 51:379-389.

Mahieu, N., D.C. Olk, and E.W. Randall. 2000b. Analysis of phospho- rus in two humic acid fractions of intensively cropped lowland rice soils by ${ }^{31}$ P NMR. Eur. J. Soil Sci. 51:391-402.

Mahieu, N., D.C. Olk, and E.W. Randall. 2002. Multinuclear magnetic resonance analysis of two humic acid fractions from lowland rice soils. J. Environ. Qual. 31:421-430.

Martin, J.P., and K. Haider. 1986. Influence of mineral colloids on turnover rates of soil organic carbon. p. 283-304. In P.M. Huang and M. Schnitzer (ed.) Interactions of soil minerals with natural organics and microbes. SSSA Spec. Pub. 17. SSSA, Madison, WI.

Nelson, D.W., and L.E. Sommers. 1975. A rapid and accurate procedure for estimation of organic carbon in soils. Proc. Indiana Acad. Sci. 84:456-462.

Olk, D.C., G. Brunetti, and N. Senesi. 1999. Organic matter in doublecropped lowland rice soils: Chemical and spectroscopic properties. Soil Sci. 164:633-649.

Olk, D.C., G. Brunetti, and N. Senesi. 2000. Decrease in humification of organic matter with intensified lowland rice cropping: A wet chemical and spectroscopic investigation. Soil Sci. Soc. Am. J. 64: $1337-1347$.

Olk, D.C., and K.G. Cassman. 2002. The role of organic matter quality in nitrogen cycling and yield trends in intensively cropped paddy soils. p. 1355-1 to1355-8. In Proc. 17th World Congress of Soil Science. 14-21 Aug. 2002, Bangkok, Thailand. International Union of Soil Sciences.

Olk, D.C., K.G. Cassman, and T.W.M. Fan. 1995. Characterization of two humic acid fractions from a calcareous vermiculitic soil: Implications for the humification process. Geoderma 65:195-208.

Olk, D.C., K.G. Cassman, N. Mahieu, and E.W. Randall. 1998. Conserved chemical properties of young humic acid fractions in tropical lowland soil under intensive irrigated rice cropping. Eur. J. Soil Sci. 49:337-349.

Olk, D.C., K.G. Cassman, E.W. Randall, P. Kinchesh, L.J. Sanger, and J.M. Anderson. 1996. Changes in chemical properties of organic matter with intensified rice cropping in tropical lowland soil. Eur. J. Soil Sci. 47:293-303.

Olk, D.C., M.C. Dancel, E. Moscoso, R.R. Jimenez, and F.M. Dayrit. 2002. Accumulation of lignin residues in organic matter fractions of lowland rice soils: A pyrolysis-GC-MS study. Soil Sci. 167:590-606.

Peng, S., and K.G. Cassman. 1998. Upper thresholds of nitrogen uptake rates and associated nitrogen fertilizer efficiencies in irrigated rice. Agron. J. 90:178-185.

Saeed, Z. 1995. Kinetics of nitrogen mineralization in anaerobic rice soils: Use of a cation exchange resin to improve in vitro anaerobic incubation methods. Ph.D. thesis, University of the Philippines, Los Baños. 159 p.

SAS Institute. 1990. The REG procedure. p. 1351-1456. In SAS/ STAT user's guide. Statistics, Vers. 6. 4th ed., Vol. 2. SAS Institute, Cary, NC.

Schnitzer, M., and M. Lévesque. 1979. Electron spin resonance as a guide to the degree of humification of peats. Soil Sci. 127:140-145.

Shumway, R.H. 1988. Time domain regression methods. p. 117-201. In Applied statistical time series analysis. Prentice Hall, Englewood Cliffs, NJ.

Stevenson, F.J., and M.A. Cole. 1999. The internal cycle of nitrogen in soil. p. 191-229. In Cycles of soil: Carbon, nitrogen, phosphorus, sulfur, micronutrients. Wiley, New York.

Stumpe, J.M., C.B. Christianson, and R.J. Buresh. 1985. An aluminum block digestion procedure for determination of total $\mathrm{N}$ in soil containing ${ }^{15} \mathrm{~N}$. Commun. Soil Sci. Plant Anal. 16:1-14.

Witt, C., K.G. Cassman, J.C.G. Ottow, and U. Biker. 1998. Soil microbial biomass and nitrogen supply in an irrigated lowland rice soil as affected by crop rotation and residue management. Biol. Fertil. Soils 28:71-80. 